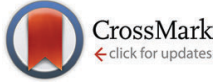

Cite this: Phys. Chem. Chem. Phys., 2015, 17, 25742

Received 14th January 2015, Accepted 25th February 2015

DOI: $10.1039 / \mathrm{c} 5 \mathrm{cp} 00221 \mathrm{~d}$

www.rsc.org/pccp

\section{IR spectrum of the protonated neurotransmitter 2-phenylethylamine: dispersion and anharmonicity of the $\mathrm{NH}_{3}{ }^{+}-\pi$ interaction $\dagger$}

\author{
Aude Bouchet, ${ }^{a}$ Markus Schütz, ${ }^{a}$ Barbara Chiavarino, ${ }^{\mathrm{b}}$ Maria Elisa Crestoni, ${ }^{\mathrm{b}}$ \\ Simonetta Fornarini ${ }^{b}$ and Otto Dopfer ${ }^{\star a}$
}

\begin{abstract}
The structure and dynamics of the highly flexible side chain of (protonated) phenylethylamino neurotransmitters are essential for their function. The geometric, vibrational, and energetic properties of the protonated neutrotransmitter 2-phenylethylamine $\left(\mathrm{H}^{+} \mathrm{PEA}\right)$ are characterized in the $\mathrm{N}-\mathrm{H}$ stretch range by infrared photodissociation (IRPD) spectroscopy of cold ions using rare gas tagging $(\mathrm{Rg}=\mathrm{Ne}$ and $\mathrm{Ar}$ ) and anharmonic calculations at the B3LYP-D3/(aug-)cc-pVTZ level including dispersion corrections. A single folded gauche conformer $(\mathbf{G})$ protonated at the basic amino group and stabilized by an intramolecular $\mathrm{NH}^{+}-\pi$ interaction is observed. The dispersion-corrected density functional theory calculations reveal the important effects of dispersion on the cation $-\pi$ interaction and the large vibrational anharmonicity of the $\mathrm{NH}_{3}^{+}$group involved in the $\mathrm{NH}^{+}-\pi$ hydrogen bond. They allow for assigning overtone and combination bands and explain anomalous intensities observed in previous IR multiplephoton dissociation spectra. Comparison with neutral PEA reveals the large effects of protonation on the geometric and electronic structure.
\end{abstract}

\section{Introduction}

The determination of the structure of neurotransmitters is a fundamental task for understanding their biological activity, in particular their recognition mechanisms. ${ }^{1}$ These essential molecules in life science activate specific key targets in the brain via molecular complementarity and self-recognition between the neurotransmitter and the receptor. ${ }^{2}$ As a consequence, the knowledge of their flexible conformation as well as their intramolecular and intermolecular interactions, including hydrogen bonds (H-bonds) and London dispersion forces, provides an understanding of these highly specific and important biological phenomena at the molecular level. To this end, the conformational landscape of a large variety of neurotransmitters has been explored by gas phase spectroscopy and quantum chemical calculations in several relevant states, namely neutral, ${ }^{3-15}$ protonated, ${ }^{16-23}$ and solvated molecules. ${ }^{24-32}$ Here, we characterize the geometric, vibrational, and electronic

\footnotetext{
${ }^{a}$ Institut für Optik und Atomare Physik, Technische Universität Berlin, Hardenbergstrasse 36, D-10623 Berlin, Germany.

E-mail:dopfer@physik.tu-berlin.de; Fax: +4930314 23018; Tel: +493031423017

${ }^{b}$ Dipartimento di Chimica e Tecnologie del Farmaco, Università degli Studi di Roma La Sapienza, P. le A. Moro 5, I-00185 Roma, Italy

$\dagger$ Electronic supplementary information (ESI) available. See DOI: 10.1039/ c5cp00221d
}
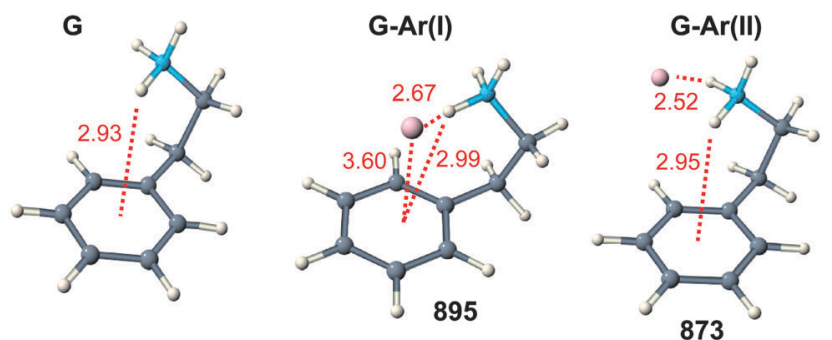

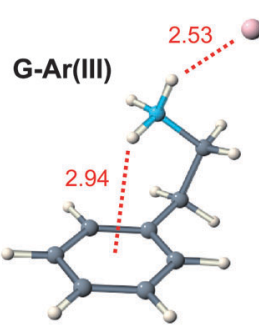

802

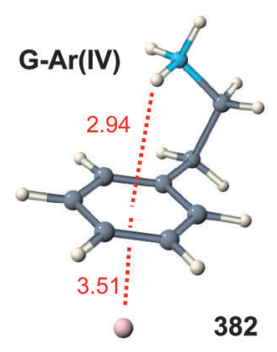

Fig. 1 Most stable structure of $\mathrm{H}^{+} \mathrm{PEA}(\mathbf{G})$ and various stable $\mathbf{G}$-Ar clusters calculated at the B3LYP-D3/aug-cc-pVTZ level. Distances and binding energies are given in $\AA$ and $\mathrm{cm}^{-1}$, respectively.

properties of protonated 2-phenylethylamine ( $\mathrm{H}^{+} \mathrm{PEA}$, Fig. 1), the parent molecule of the fundamental class of aromatic ethylamino neurotransmitters, using infrared photodissociation (IRPD) of ions tagged with rare gas ligands and quantum chemical calculations. 
As an initial step, the study of such neurotransmitter compounds isolated in the gas phase is necessary because it provides an accurate description without any interference from the biological environment, which can directly be compared to high-level quantum chemical calculations. Moreover, to provide a realistic description of neurotransmitters as found in the biological medium, it is necessary to take protonation into account, because the physiological $\mathrm{pH}$ value (7.4) in cell fluid and blood plasma is usually sufficient to convert these molecules into their protonated form. Protonation drastically affects the binding properties of neurotransmitters with their environment such as the solvent and the receptor. Like many other biological aromatic amines, the favourite protonation site of most phenylethylamino neurotransmitters is the amino group $\left(\mathrm{RNH}_{3}{ }^{+}\right) \cdot{ }^{16-23}$ Thus, the positive charge located on the $\mathrm{NH}_{3}{ }^{+}$ terminus of the ethylamino side chain strongly attracts nucleophilic ligands.

2-Phenylethylamine (PEA), one of the simplest aromatic biogenic amines, is the building block of around 200 neurotransmitters (e.g., adrenaline, dopamine, serotonin) and neurologically active molecules such as psychoactive drugs (e.g., ecstasy and other amphetamines). Its flexible side chain enables neutral PEA to adopt various low-energy conformations with rather small energy barriers between them. Raman spectroscopy combined with quantum chemical calculations afforded a description of liquid PEA as a function of temperature. ${ }^{33}$ The five possible stable conformers of PEA identified in the liquid differ by the orientation of their side chain. In the two unfolded anti conformers, the ethylamino group points away from the aromatic ring, while it points toward the phenyl group in the three folded gauche conformers. As the latter form an intramolecular $\mathrm{NH}-\pi \mathrm{H}$-bond between the amino group and the aromatic ring, they are more stable than the anti conformers. The five PEA conformers have been detected at room temperature in liquid PEA and form an intermolecular H-bonded network via $\mathrm{NH}-\mathrm{N}$ interactions. ${ }^{33}$ The population of anti conformers increases with increasing temperature, and might be dominant at room temperature. The conclusions derived from comparing spectra in solution with calculations for isolated molecules have however to be taken with some caution because solvent effects on the structure, relative energy, isomerization barriers, vibrational spectra, and protonation state have been ignored in this study. ${ }^{33}$ Nonetheless, the results obtained in solution agree with the gas phase conclusions obtained from ultraviolet, ${ }^{3,26,34}$ microwave, ${ }^{47}$ and ionization-loss stimulated Raman ${ }^{10}$ spectra in molecular beams, although these techniques have only detected the four most stable conformers (two anti and two gauche). Neutral PEA undergoes hydration-induced conformational locking when forming a dimer with water, PEA- $\mathrm{H}_{2} \mathrm{O} \cdot{ }^{31,32,35}$ The four conformers observed for bare PEA collapse into a single PEA- $\mathrm{H}_{2} \mathrm{O}$ isomer in the molecular beam, in which $\mathrm{H}_{2} \mathrm{O}$ acts as $\mathrm{H}$-bond donor to the lone pair of the amino group. This locking effect is also observed for related bioactive molecules such as tryptamine, also an aromatic amine with an ethylamino side chain. ${ }^{36}$

Surprisingly, the reported density functional theory (DFT) calculations yield only two conformers of the $\mathrm{PEA}^{+}$radical cation, ${ }^{37}$ namely a more stable anti conformer and a less stable gauche isomer, i.e. the energetic order of gauche and anti isomers reverses upon ionization, because the $\mathrm{NH}-\pi$ interaction becomes repulsive. The isomer-selective photoelectron spectra of the four neutral PEA isomers provide evidence for charge delocalization from the aromatic ring into the chain of $\mathrm{PEA}^{+}$upon ionization, with the proportion strongly depending on the ion conformation (anti or gauche).

In a recent systematic study of the effects of the length of the side chain on the cation- $\pi$ interaction in protonated phenylalkylamines by IR multiphoton dissociation (IRMPD) spectroscopy at room temperature and DFT calculations, $\mathrm{H}^{+} \mathrm{PEA}$ is found in a folded gauche conformation (G, Fig. 1) strongly stabilized by an intramolecular $\mathrm{NH}^{+}-\pi$ interaction. ${ }^{23}$ At the $\omega \mathrm{B} 97 \mathrm{X}-\mathrm{D} / 6-311++\mathrm{G}(\mathrm{d}, \mathrm{p})$ level, the anti conformer $(\mathbf{A})$ is calculated to be $1755 \mathrm{~cm}^{-1}$ higher in energy and it has not been detected experimentally. Similar cation $-\pi$ interactions have been noticed in related protonated phenylethylamino neurotransmitters, such as dopamine, serotonin, and histamine. ${ }^{20-22}$ In addition, the electronic properties of a series of protonated aromatic amines including $\mathrm{H}^{+}$PEA have been explored by UV photodissociation in a cryogenic ion trap and $a b$ initio calculations of the gauche conformer. ${ }^{38}$ The electronic structure of the aromatic ring is only weakly perturbed by protonation at the amino terminus, suggesting that the excess charge is localized mainly on the side chain. $\mathrm{H}^{+}$PEA differs from the other studied aromatic amines by the presence of a nearby quasi-dissociative $\pi \sigma^{*}$ excited electronic state along the $\mathrm{N}-\mathrm{H}$ coordinate of the ammonium group, which leads to the rupture of the $\mathrm{C} \alpha-\mathrm{C} \beta$ (C8-C7) bond along with proton transfer from $\mathrm{NH}_{3}{ }^{+}$to the aromatic ring. ${ }^{38}$

Here, we characterize $\mathrm{H}^{+} \mathrm{PEA}-\mathrm{Rg}_{n}$ clusters with $\mathrm{Rg}=\mathrm{Ne}$ $(n=1-3)$ and $\operatorname{Ar}(n=1,2)$ generated in a cold molecular beam by IRPD photodissociation in the $\mathrm{N}-\mathrm{H}$ stretch range and dispersion-corrected DFT calculations including anharmonicity (B3LYP-D3). The main motivation for the current study can be summarized as follows. The comparison of the previously reported IRMPD spectra of bare $\mathrm{H}^{+}$PEA ions recorded in room-temperature ion traps in both the fingerprint and $\mathrm{N}-\mathrm{H}$ stretch ranges with linear IR absorption spectra obtained from quantum chemical calculations reveals substantial intensity anomalies, band broadening, and frequency shifts (Fig. 2), which have been attributed to the multiple-photon absorption process of IRMPD, the elevated temperature, and effects of anharmonicity without further analysis. ${ }^{23}$ Multiple rare-gas tagging of $\mathrm{H}^{+}$PEA in a supersonic expansion leads to much colder ions with sharper spectra and reduces the dissociation energy such that single-photon IRPD spectra can be recorded, which can directly be compared to the calculated linear IR absorption spectra. Although the effects of the $\mathrm{Rg}$ atoms on the $\mathrm{H}^{+} \mathrm{PEA}$ properties are expected to be small, their magnitude can be evaluated by extrapolating the effects of $\mathrm{Rg}=\mathrm{Ar}$ and $\mathrm{Ne}$ to zero solvation ${ }^{39-42}$ and including the $\mathrm{Rg}$ ligands in the calculations. In addition, the current DFT calculations consider explicitly both dispersion (DFT-D3) and vibrational anharmonicity, which have been predicted to be particularly important for 


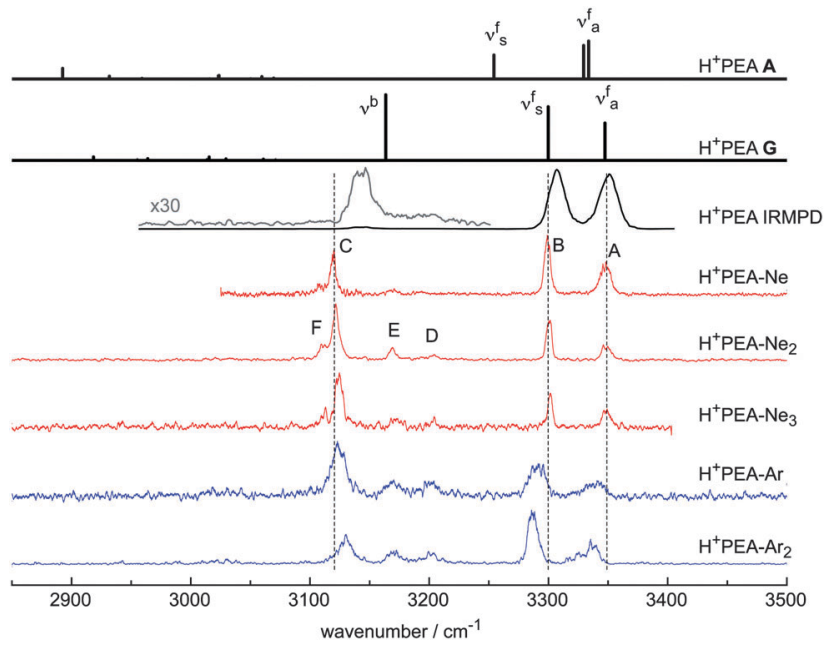

Fig. 2 IRPD spectra of $\mathrm{H}^{+} \mathrm{PEA}-\mathrm{Rg}_{n}$ with $\mathrm{Rg}=\mathrm{Ne}(n=1-3)$ and $\operatorname{Ar}(n=1,2)$ compared to the IRMPD spectrum ${ }^{23}$ of $\mathrm{H}^{+} \mathrm{PEA}$ and linear harmonic IR absorption spectra (scaled by 0.9586 ) of the $\mathbf{G}$ and $\mathbf{A}$ conformers of $\mathrm{H}^{+} \mathrm{PEA}$ calculated at the B3LYP-D3/aug-cc-pVTZ level. The positions and widths of the transitions observed $(\mathrm{A}-\mathrm{F})$ are listed in Table 1, along with the suggested vibrational assignment. Part of the IRMPD spectrum is vertically expanded by a factor of 30 .

cation- $\pi$ interactions involving $\mathrm{NH}_{3}{ }^{+}$groups. ${ }^{20-23,43,44}$ The anharmonic calculations conducted at the B3LYP-D3/cc-pVTZ level yield frequencies and IR intensities of fundamentals, overtones, and combination bands, which provide more realistic IR spectra than the previously used approach of linearly scaled harmonic spectra. In particular, generalized second order vibrational perturbation theory on potentials generated at the B3LYP-D3 level has been shown to be an effective approach for predicting reliable anharmonic spectra including both frequencies and IR intensities. $^{45}$

\section{Experimental and computational methods}

The IRPD spectra of mass-selected $\mathrm{H}^{+} \mathrm{PEA}-\mathrm{Rg}_{n}$ cluster ions with $\mathrm{Rg}=\operatorname{Ar}(n=1,2)$ and $\mathrm{Ne}(n=1-3)$ shown in Fig. 2 are recorded in a tandem quadrupole mass spectrometer coupled to an electron impact ionization source and an octopole ion guide. ${ }^{46,47}$ Liquid PEA purchased from Sigma-Aldrich $(>99.5 \%)$ is used without further purification. Cold $\mathrm{H}^{+} \mathrm{PEA}-\mathrm{Rg}_{n}$ clusters are produced by electron and chemical ionization of PEA close to the nozzle orifice. A pulsed supersonic plasma expansion is generated and subsequent clustering reactions occur in the high-pressure regime of this expansion. The expanding gas mixture is produced by passing $\operatorname{Ar}$ ( 5 bar) or Ne (12 bar) carrier gas through a reservoir filled with PEA and heated to $330 \mathrm{~K}$. Protonation of PEA occurs by self-protonation reactions and/or by exothermic proton transfer from protonated water clusters produced from water impurities in the gas inlet system. $\mathrm{H}^{+} \mathrm{PEA}-\mathrm{Rg}_{n}$ ions are mass selected by the first quadrupole and irradiated in an adjacent octopole with a tuneable IR laser pulse generated by an optical parametric oscillator (IR-OPO) pumped by a nanosecond Q-switched Nd:YAG laser. The IR-OPO laser is characterized by a pulse energy of 2-5 $\mathrm{mJ}$ in the $2800-3500 \mathrm{~cm}^{-1}$ range, a repetition rate of $10 \mathrm{~Hz}$, and a bandwidth of $1 \mathrm{~cm}^{-1}$. Calibration of the IR laser frequency to better than $1 \mathrm{~cm}^{-1}$ is accomplished by a wavemeter. Resonant excitation into vibrational resonances of $\mathrm{H}^{+} \mathrm{PEA}-\mathrm{Rg}_{n}$ induces the evaporation of all $\mathrm{Rg}$ ligands. The rupture of the weak intermolecular bonds is the only fragment channel observed. The $\mathrm{H}^{+}$PEA fragment ions are selected by the second quadrupole and monitored by a Daly detector as a function of the IR laser frequency to obtain the IRPD spectra of the $\mathrm{H}^{+} \mathrm{PEA}-\mathrm{Rg}_{n}$ parent clusters. Although the IRPD spectra are not normalized for laser intensity variations monitored by a pyroelectric detector, the relative intensities of widely-spaced peaks are believed to be accurate to within a factor of 2 , mainly due to variations in the spatial overlap between the ion and laser beams. To establish and confirm the composition of a given cluster ion, collision-induced dissociation spectra are recorded. For this purpose, the octopole is filled with $\mathrm{N}_{2}$ up to $10^{-5}$ mbar, which results in collisions with $\sim 10 \mathrm{eV}$ collision energy in the laboratory frame. Recent applications of this IRPD approach of tagged ions in our laboratory include hydrocarbon ions, ${ }^{48-57}$ silicon-containing ions, ${ }^{58-60}$ and biological molecules and their hydrates. ${ }^{61-66}$

DFT calculations ${ }^{67}$ are carried out at the B3LYP-D3/aug-cc-pVTZ level to determine the geometric, vibrational, and energetic properties of the $\mathrm{H}^{+} \mathrm{PEA}$ conformers and their $\mathrm{H}^{+} \mathrm{PEA}-\mathrm{Rg}_{n}$ clusters. The Grimme dispersion correction ${ }^{68}$ is used to accurately describe the dispersion forces, which are particularly relevant for the intermolecular bonds to the $\mathrm{Rg}$ atoms and the intramolecular $\mathrm{NH}^{+}-\pi$ interaction of $\mathrm{H}^{+}$PEA. Relative electronic energies $\left(E_{\mathrm{e}}\right)$ and intermolecular interaction energies $\left(D_{\mathrm{e}}\right)$ are corrected for harmonic zero-point energy to yield $E_{0}$ and $D_{0}$ values. The binding energies $D_{0}$ are further corrected for basis set superposition error. Harmonic frequencies in the $\mathrm{N}-\mathrm{H}$ stretch range are scaled by 0.9586 to match the experimental free $\mathrm{N}-\mathrm{H}$ stretch frequencies of the $\mathbf{G}$ conformer of $\mathrm{H}^{+}$PEA estimated from the $\mathrm{H}^{+} \mathrm{PEA}-\mathrm{Ne}$ spectrum. Finally, anharmonic vibrational calculations at the B3LYP-D3/cc-pVTZ level are performed for the $\mathbf{G}$ and A conformers of $\mathrm{H}^{+}$PEA as well as the most stable $\mathrm{H}^{+}$PEA-Rg clusters using the generalized second order vibrational perturbation theory approach as implemented in GAUSSIAN09 ${ }^{67}$ to rationalize additional transitions observed in the IRPD spectra and intensity particularities previously observed in the IRMPD spectra. ${ }^{23}$ Details of this technique and its theoretical formalism ${ }^{69,70}$ have been reviewed recently. ${ }^{71}$ Briefly, the calculation of frequencies and IR intensities of fundamentals along with overtones and combination bands involving two vibrational quanta relies on the anharmonic potential energy surface expanded up to quartic terms and the electric dipole moment surface expanded up to cubic terms. Extensive test calculations including aromatic molecules reveal that the dispersion-corrected B3LYP-D3 functional outperforms in accuracy other recently developed popular functionals, such as CAM-B3LYP, M06-2X, and $\omega$ B97X-D when using basis sets of at least triple-zeta quality. ${ }^{45,71}$ If not mentioned otherwise, all computed spectra shown in the figures are drawn 
to the same scale. The charge distribution is discussed using the natural bond orbital (NBO) analysis.

\section{Results and discussion}

\subsection{IRPD spectra of $\mathrm{H}^{+} \mathrm{PEA}-\mathrm{Rg}_{\boldsymbol{n}}$ clusters}

The single-photon IRPD spectra recorded in the $\mathrm{N}-\mathrm{H}$ and $\mathrm{C}-\mathrm{H}$ stretch range $\left(2800-3500 \mathrm{~cm}^{-1}\right)$ for cold $\mathrm{H}^{+} \mathrm{PEA}-\mathrm{Rg}_{n}$ cluster ions with $\operatorname{Rg}=\operatorname{Ar}(n=1,2)$ and $\mathrm{Ne}(n=1-3)$ generated in a molecular beam are compared in Fig. 2 to the previously reported IRMPD spectrum of bare $\mathrm{H}^{+}$PEA recorded at room temperature in an ion trap. ${ }^{23}$ For comparison, the linear IR absorption spectra calculated for the two possible conformers $\mathbf{A}$ and $\mathbf{G}$ are also shown. The $\mathrm{N}-\mathrm{H}$ stretch fundamentals $\left(\nu_{\mathrm{NH}}\right)$ provide detailed information about the conformation of the $\mathrm{H}^{+} \mathrm{PEA}$ chromophore and the $\mathrm{Rg}$ binding sites. The transitions A-C are assigned to the three $\nu_{\mathrm{NH}}$ fundamentals of the ammonium group. The transitions $\mathrm{D}$ and $\mathrm{E}$ are attributed to overtone and combination bands, while band $\mathrm{F}$ probably arises from splittings of different tagging sites. The aromatic and aliphatic $\nu_{\mathrm{CH}}$ fundamentals occur also in this frequency range but their IR intensities are much weaker compared to those of $\nu_{\mathrm{NH}}$ and thus are below the current detection limit. The positions and widths of the transitions observed are listed in Table 1, along with their vibrational assignments.

Inspection of Fig. 2 immediately suggests an assignment of all experimental spectra exclusively to the most stable $\mathbf{G}$ isomer (Fig. 1), for which good overall agreement is observed for all three intense $\nu_{\mathrm{NH}}$ fundamentals $\mathrm{A}-\mathrm{C}\left(\nu_{\mathrm{a}}^{\mathrm{f}}, \nu_{\mathrm{s}}^{\mathrm{f}}, \nu^{\mathrm{b}}\right)$. Thus, $\mathrm{Rg}$ tagging does not change the conformation of the $\mathrm{H}^{+}$PEA ion and the ligands can to first order be considered as messengers. There are, however, small variations in the positions of these transitions in the IRPD spectra of the $\mathrm{H}^{+} \mathrm{PEA}-\mathrm{Rg}_{n}$ clusters as a function of $n$ and $\mathrm{Rg}$, which will be exploited below to derive information about the $\mathrm{Rg}$ binding sites and the corresponding interaction energies.

Although the IRMPD spectrum of bare $\mathrm{H}^{+}$PEA shows overall good qualitative agreement with the IRPD spectra of the $\mathrm{H}^{+} \mathrm{PEA}-\mathrm{Rg}_{n}$ clusters and the monomer spectrum calculated for $\mathbf{G}$, there are significant deviations with respect to band positions, relative intensities, and widths of the transition. As will be shown below, the IRPD spectra of the cold $\mathrm{H}^{+} \mathrm{PEA}-\mathrm{Ne}_{n}$ clusters can be considered as close approximation to the linear absorption spectrum of $\mathrm{H}^{+} \mathrm{PEA}$, with frequency deviations of less than $8 \mathrm{~cm}^{-1}$ and only minor modifications of the relative IR intensities ( < factor 1.5) upon Ne complexation. In contrast, the strongly nonlinear IRMPD spectrum shows frequency deviations of up to $\sim 20 \mathrm{~cm}^{-1}$ to the blue and intensity deviations up to a factor of $\sim 25$ (for band $\mathrm{C}$ ). These substantial modifications are attributed to the well-known consequences of the multiplephoton absorption process ${ }^{72,73}$ responsible for IRMPD and will be considered in more detail in Section 3.3.

The widths of the transitions observed in the IRPD spectra of the cold $\mathrm{H}^{+} \mathrm{PEA}-\mathrm{Rg}_{n}$ clusters tend to decrease with increasing $n$ and decreasing size of the Rg atom (Table 1). For example, the widths of transition $\mathrm{B}$ are $5-6 \mathrm{~cm}^{-1}$ for $\mathrm{H}^{+} \mathrm{PEA}-\mathrm{Ne}_{1-3}$ and 17 and $11 \mathrm{~cm}^{-1}$ for $\mathrm{H}^{+} \mathrm{PEA}-\mathrm{Ar}_{1,2}$. The maximum internal energy in the $\mathrm{H}^{+} \mathrm{PEA}-\mathrm{Rg}_{n}$ clusters produced in the molecular beam is given by the binding energy of the most weakly bound ligand, which decreases with $n$ but increases with the size of the Rg atom. Interestingly, the widths observed in the IRMPD spectrum of $\mathrm{H}^{+}$PEA are similar to those in the IRPD spectrum of $\mathrm{H}^{+}$PEA-Ar $\left(\sim 20 \mathrm{~cm}^{-1}\right)$.

\subsection{Harmonic calculations}

3.2.1 $\mathbf{H}^{+}$PEA monomer. Similar to related aromatic ethylamino neurotransmitters, ${ }^{20-22}$ the amino group is by far the most stable protonation site of PEA and the resulting ammonium ion is lower in energy by at least $100 \mathrm{~kJ} \mathrm{~mol}^{-1}$ than any other isomer protonated at the aromatic ring (not shown). The potential energy surface of the side chain conformation of the ammonium ion is explored in a relaxed potential energy surface scan along the dihedral angle $\theta=\theta_{\mathrm{C} 1 \mathrm{C} 7 \mathrm{C} 8 \mathrm{~N}}$ corresponding to a rotation around the $\mathrm{C} 7-\mathrm{C} 8$ bond (Fig. 3). The angle $\theta$ is varied in steps of $1^{\circ}$ and all other coordinates are relaxed. As the resulting potential is symmetric with respect to $\theta=0^{\circ}$, only the part between $-180^{\circ}$ and $0^{\circ}$ is shown. The global minimum corresponds to the folded $\mathbf{G}$ conformer at $\theta=-54^{\circ}$. The two equivalent $\mathbf{G}$ conformers at $\theta= \pm 54^{\circ}$ are separated by a barrier of $1056 \mathrm{~cm}^{-1}$ at the transition state TS1 with $C_{\mathrm{s}}$ symmetry at $\theta=0^{\circ}$. They are mirror images through the symmetry plane of TS1 and correspond to the two enantiomers of a chiral molecule arising from symmetric interactions between the ammonium group and the $\pi$ electron system of the aromatic ring. The extended $\mathbf{A}$ conformer with $C_{\mathrm{s}}$ symmetry

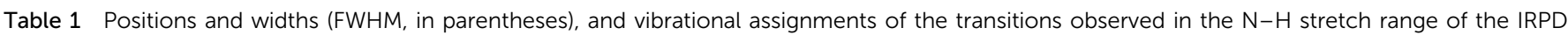
spectra of $\mathrm{H}^{+} \mathrm{PEA}-\mathrm{Rg}_{n}$ clusters and the IRMPD spectrum of bare $\mathrm{H}^{+} \mathrm{PEA}$ compared to frequencies calculated for the $\mathrm{G}$ conformer of $\mathrm{H}^{+} \mathrm{PEA}$

\begin{tabular}{|c|c|c|c|c|c|c|}
\hline & A & $\mathrm{B}$ & $\mathrm{C}$ & $\mathrm{D}$ & $\mathrm{E}$ & $\mathrm{F}$ \\
\hline $\mathrm{H}^{+} \mathrm{PEA}-\mathrm{Ne}$ & $3348(11)$ & $3299(6)$ & $3120(5)$ & & $3169(11)$ & $3108(5)$ \\
\hline $\mathrm{H}^{+} \mathrm{PEA}-\mathrm{Ne}_{2}$ & $3350(11)$ & $3301(5)$ & $3122(7)$ & $3204(7)$ & $3169(7)$ & $3111(7)$ \\
\hline $\mathrm{H}^{+} \mathrm{PEA}-\mathrm{Ne}_{3}$ & $3349(9)$ & $3302(5)$ & $3125(8)$ & $3204(5)$ & $3171(8)$ & $3113(5)$ \\
\hline $\mathrm{H}^{+} \mathrm{PEA}-\mathrm{Ar}$ & $3340(20)$ & $3291(17)$ & $3123(15)$ & $3201(10)$ & $3169(15)$ & \\
\hline $\mathrm{H}^{+} \mathrm{PEA}-\mathrm{Ar}_{2}$ & $3337(11)^{c}$ & $3286(11)$ & $3130(13)$ & $3202(7)$ & $3170(11)$ & \\
\hline $\mathrm{H}^{+}$PEA (IRMPD) ${ }^{a}$ & $3351(17)$ & $3307(16)$ & $3143(20)$ & & & \\
\hline $\mathbf{G}^{b}$ & $3348(90)$ & $\begin{array}{l}3299(123) \\
\nu_{\mathrm{s}}^{\mathrm{f}}\end{array}$ & $\nu^{3164(150)}$ & $d$ & $d$ & \\
\hline
\end{tabular}

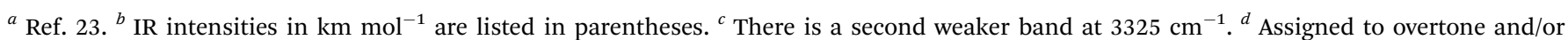
combination bands (see text). 


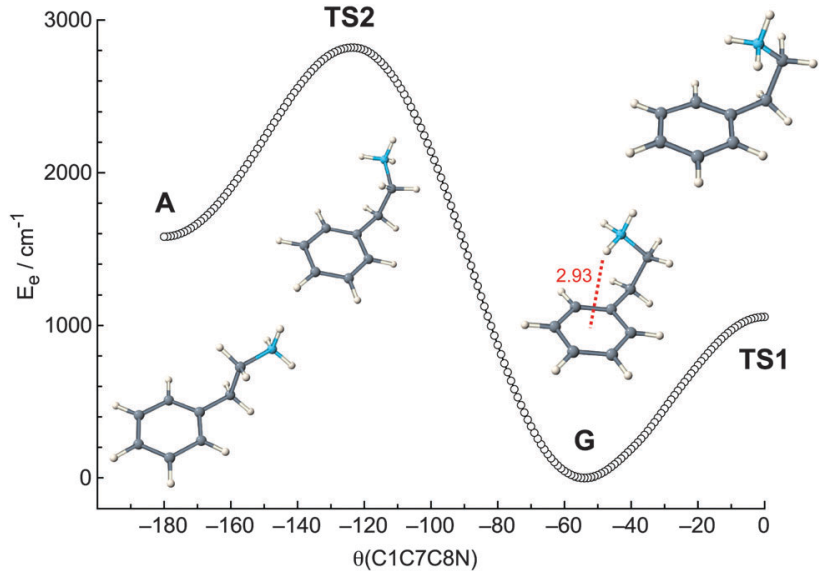

Fig. 3 Relaxed potential energy surface of the side chain conformation of $\mathrm{H}^{+} \mathrm{PEA}$ along the dihedral angle $\theta_{\mathrm{C} 1 \mathrm{C} 7 \mathrm{C} 8 \mathrm{~N}}$ corresponding to a rotation around the C7-C8 bond (B3LYP-D3/aug-cc-pVTZ). The angle $\theta$ is varied in steps of $1^{\circ}$ and all other coordinates are relaxed. As the potential is symmetric with respect to $\theta=0^{\circ}$, only the part between $-180^{\circ}$ and $0^{\circ}$ is shown.

at $\theta=-180^{\circ}$ is $1580 \mathrm{~cm}^{-1}$ less stable than $\mathbf{G}$. The transition state TS2 for $\mathbf{A} \leftrightarrow \mathbf{G}$ interconversion occurs at $\theta=-124^{\circ}$ with $E_{\mathrm{e}}=$ $2819 \mathrm{~cm}^{-1}$, corresponding to a barrier of $1239 \mathrm{~cm}^{-1}$ for $\mathbf{A} \rightarrow \mathbf{G}$ isomerization. The salient geometrical and energetic data (including zero-point energy) of the fully optimized stationary points on this potential energy surface are listed in Table 2. Further geometric parameters and the NBO charge distribution of the $\mathbf{G}$ and A minima are available in Fig. S1 and S2 in ESI, $\dagger$ respectively.

Another characteristic parameter of the cation $-\pi$ interaction in $\mathbf{G}$ is the distance between the $\mathrm{NH}^{+}$proton donor and the center of the phenyl ring. Without dispersion correction (B3LYP), $R(\mathrm{H}-\pi)$ is calculated as $2.99 \AA$ and it contracts to $2.93 \AA$ when dispersion is included (B3LYP-D3). Thus, the empirical D3 dispersion correction strengthens the $\mathrm{NH}^{+}-\pi$ interaction in $\mathbf{G}^{23}$ As a result, the $\mathbf{G}$ conformer is further stabilized relative to A by $362 \mathrm{~cm}^{-1}\left(4.3 \mathrm{~kJ} \mathrm{~mol}^{-1}\right)$. This amount of additional stabilization by dispersion is similar to values calculated for related protonated neurotransmitters. ${ }^{20-22}$ Interestingly, the marked decrease of the $\mathrm{NH}^{+}-\pi$ distance upon inclusion of dispersion is not accompanied by any significant increase of the $\mathrm{N}-\mathrm{H}$ proton donor bond length, which remains constant at $1.0301 \AA$, but by a more pronounced folding of the side chain at the dispersion-corrected level.

The $\mathrm{N}-\mathrm{H}$ bond lengths of the $\mathrm{NH}_{3}{ }^{+}$group depend sensitively on the conformation of the side chain (Table 2 and Fig. S3 in $\mathrm{ESI} \dagger)$. In the $\mathbf{G}$ conformer, the $\mathrm{N}-\mathrm{H}$ proton donor bond in the cation $-\pi$ interaction $(1.0301 \AA$ ) is roughly $10 \mathrm{~mA}$ longer than the two free $\mathrm{N}-\mathrm{H}$ bonds (1.0201 and 1.0212 $\AA$ ). In the $\mathbf{A}$ conformer, all three free $\mathrm{N}-\mathrm{H}$ bond lengths are the same to within $0.0004 \AA$, with an average of $1.0220 \AA$, i.e. they are somewhat longer than the free $\mathrm{N}-\mathrm{H}$ bonds in $\mathbf{G}$. These different $\mathrm{N}-\mathrm{H}$ bond lengths translate directly into the $\nu_{\mathrm{NH}}$ frequencies of $\mathbf{G}$ and $\mathbf{A}$, and their IR stick spectra are compared in Fig. 2. In A, the three nearly degenerate free $\mathrm{N}-\mathrm{H}$ local modes are strongly coupled, leading to a lower frequency symmetric stretch $\left(\nu_{\mathrm{s}}^{\mathrm{f}}=3254 \mathrm{~cm}^{-1}\right)$ and two higher frequency asymmetric stretches $\left(\nu_{\mathrm{a}}^{\mathrm{f}}=3330\right.$ and $3334 \mathrm{~cm}^{-1}$ ) split by only $4 \mathrm{~cm}^{-1}$. In $\mathbf{G}$, the bound $\mathrm{N}-\mathrm{H}$ stretch involved in the $\mathrm{NH}^{+}-\pi$ interaction is rather isolated and occurs at low frequency $\left(\nu^{\mathrm{b}}=3164 \mathrm{~cm}^{-1}\right)$ with somewhat enhanced IR activity. The two remaining free $\mathrm{N}-\mathrm{H}$ stretch oscillators are strongly coupled, producing symmetric and asymmetric normal modes at $\nu_{\mathrm{s}}^{\mathrm{f}}=3299$ and $\nu_{\mathrm{a}}^{\mathrm{f}}=3348 \mathrm{~cm}^{-1}$ with a comparably large splitting of $\sim 50 \mathrm{~cm}^{-1}$. As a result of the $\mathrm{NH}^{+}-\pi$ bonding, the average $\mathrm{N}-\mathrm{H}$ stretch frequency in $\mathbf{G}$ is lower than in $\mathbf{A}$ (3270 versus $3306 \mathrm{~cm}^{-1}$ ). Significantly, there is essentially no effect of dispersion on the $\mathrm{N}-\mathrm{H}$ bond lengths $(<0.0002 \AA)$ and stretch frequencies $\left(<1 \mathrm{~cm}^{-1}\right)$.

As expected, the $\mathrm{N}-\mathrm{H}$ stretch range is highly sensitive to the conformation of the side chain in $\mathrm{H}^{+}$PEA. Inspection of Fig. 2 immediately reveals that the experimental IRPD spectra of the cold $\mathrm{H}^{+} \mathrm{PEA}-\mathrm{Rg}_{n}$ clusters generated by chemical ionization in a molecular beam and the IRMPD spectrum of internally warm $\mathrm{H}^{+} \mathrm{PEA}$ ions generated by electrospray ionization are both completely dominated by the $\mathbf{G}$ conformer. The lack of any

Table 2 Selected geometrical ( $\AA$, degree) and energetic parameters $\left(\mathrm{cm}^{-1}\right)$ of minima and transition states of $\mathrm{H}^{+} \mathrm{PEA}$ and various isomers of the G-Rg clusters with $\mathrm{Rg}=\mathrm{Ne}$ and $\mathrm{Ar}$ calculated at the B3LYP-D3/aug-cc-pVTZ level

\begin{tabular}{|c|c|c|c|c|c|c|c|}
\hline & $\theta_{\mathrm{C} 1 \mathrm{C} 7 \mathrm{C} 8 \mathrm{~N}}$ & $\theta_{\mathrm{C} 2 \mathrm{C} 1 \mathrm{C} 7 \mathrm{C} 8}$ & $R(\mathrm{H}-\pi)^{a}$ & $R(\mathrm{~N}-\mathrm{H})^{b}$ & $R(\mathrm{Rg}-\mathrm{H}) / R(\mathrm{Rg}-\pi)$ & $E_{0}\left(E_{\mathrm{e}}\right)^{b}$ & $D_{0}$ \\
\hline $\mathbf{A}\left(C_{\mathrm{s}}\right)$ & -180 & 89 & - & 1.02211 .02211 .0217 & - & $1564(1580)$ & - \\
\hline TS1 $\left(C_{\mathrm{s}}\right)$ & 0 & 88 & 3.05 & 1.02401 .02041 .0240 & - & $1090(1056)$ & - \\
\hline G-Ar(I) & -56 & 98 & 2.99 & 1.02941 .02001 .0209 & $2.67 / 3.60$ & $0(0)$ & 895 \\
\hline G-Ar(II) & -54 & 99 & 2.95 & 1.02911 .01981 .0226 & $2.52 /-$ & $22(21)$ & 873 \\
\hline G-Ne(I) & -55 & 98 & 2.95 & 1.02981 .02001 .0210 & $2.33 / 3.32$ & $0(0)$ & 319 \\
\hline G-Ne(II) & -54 & 100 & 2.93 & 1.03001 .01991 .0212 & $2.25 /-$ & $5(10)$ & 314 \\
\hline G-Ne(III) & -54 & 101 & 2.94 & 1.02981 .02011 .0210 & $2.25 /-$ & $9(45)$ & 310 \\
\hline G-Ne(IV) & -54 & 100 & 2.93 & 1.03011 .02011 .0212 & $-/ 3.19$ & $185(246)$ & 134 \\
\hline
\end{tabular}

${ }^{a} R(\mathrm{H}-\pi)$ is the $\mathrm{NH}-\pi$ distance between the center of the aromatic ring and the nearest $\mathrm{NH}$ proton. ${ }^{b} E_{0 / \mathrm{e}}$ are the electronic energies relative to the most stable conformer. They are corrected for BSSE for Rg clusters. $E_{0}$ is corrected for zero-point energy. 
signal near $3250 \mathrm{~cm}^{-1}$ in all experimental spectra indicates that the presence of the less stable A conformer is below the detection limit under all conditions considered. In both isomers, the aromatic and aliphatic $\mathrm{C}-\mathrm{H}$ stretch transitions occur below $3100 \mathrm{~cm}^{-1}$ and are too weak to be detected under the present sensitivity. Therefore, they are not considered further.

3.2.2 $\mathbf{H}^{+}$PEA-Rg $\boldsymbol{n}$ clusters. To identify the preferred $\mathrm{Rg}$ binding sites of $\mathrm{H}^{+} \mathrm{PEA}$, the geometries, energies, and harmonic frequencies of selected $\mathrm{H}^{+} \mathrm{PEA}-\mathrm{Rg}$ dimers with $\mathrm{Rg}=$ $\mathrm{Ar}$ and Ne are calculated at the B3LYP-D3/aug-cc-pVTZ level (Tables 2, 3 and Fig. 1, 4). We consider only clusters with a $\mathbf{G}$ conformation of $\mathrm{H}^{+}$PEA because only these are observed experimentally. The four $\mathrm{Rg}$ binding sites investigated include all three acidic and strongly attractive $\mathrm{NH}$ protons (I-III) of the positively charged $\mathrm{NH}_{3}{ }^{+}$group ${ }^{74-79}$ as well as the aromatic ring (IV) with strong dispersion attraction (see Fig. 1 for the G-Ar geometries). ${ }^{80,81}$ The NBO analysis detailed in Fig. S2 in ESI $\dagger$ shows that the positive charge in $\mathbf{G}$ is mainly localized on the side chain $(q=+967 \mathrm{me})$, while the phenyl ring is mostly neutral $(q=+34 \mathrm{me})$. In the side chain, the charge is concentrated on the $\mathrm{NH}_{3}{ }^{+}$group $\left(q=+646\right.$ me) and the adjacent $\mathrm{C} 8 \mathrm{H}_{2}$ group (+275 me). In general, the Ne binding energies are smaller than the Ar binding energies by a factor of $\sim 3$, which is close to the ratio of their static polarisabilities ( 0.396 and $\left.1.642 \AA^{3}\right) .{ }^{82}$ This trend is expected because both the dispersion and the chargeinduced dipole attraction scale linearly with the polarisability, and the bond distances are roughly independent of the $\mathrm{Rg}$ atom (Table 2). ${ }^{39}$

The binding energies of the three most stable isomers of G-Rg(I-III), in which the $\mathrm{Rg}$ binds to the $\mathrm{NH}$ protons are quite similar and fall for $\mathrm{Rg}=\mathrm{Ar}$ in the range $D_{0}=802-895 \mathrm{~cm}^{-1}$. In the most stable G-Ar(I) isomer with $D_{0}=895 \mathrm{~cm}^{-1}$, the Ar ligand benefits from both the dispersion interaction with the neutral $\pi$-electron system $(R=3.60 \AA)$ and the attraction by the positive $\mathrm{NH}^{+}$proton $(R=2.67 \AA)$. The Ar atom forces the ethylammonium chain to slightly deviate from the position it adopts in the monomer in order to favour the $\mathrm{Ar}-\pi$ interaction, and $\theta_{\mathrm{C} 1 \mathrm{C} 7 \mathrm{C} 8 \mathrm{~N}}$ opens by $2^{\circ}$ (Table 2 ). This steric constraint involved in the twofold interaction implies that the $\mathrm{NH}^{+}-\pi$ interaction in G-Ar(I) is somewhat weaker and the $\mathrm{NH}^{+}-\pi$ distance $(R=2.99 \AA)$ is longer than in bare $\mathbf{G}(R=2.93 \AA)$. In the next two isomers with a $\mathrm{NH}^{+}-\mathrm{Ar}$ interaction to the free $\mathrm{NH}$ protons, $\mathrm{G}-\mathrm{Ar}$ (II,III), there is no such steric hindrance for Ar induced by the phenyl ring, leading to

Table 3 Scaled (by 0.9586) harmonic frequencies $\left(\mathrm{cm}^{-1}\right)$ and IR intensities ( $\mathrm{km} \mathrm{mol}^{-1}$, in parentheses) of the $\nu_{\mathrm{NH}}$ fundamentals of $\mathbf{G}$ and various G-Rg isomers calculated at the B3LYP-D3/aug-cc-pVTZ level (Fig. 1 and 4)

\begin{tabular}{llll}
\hline & $\nu^{\mathrm{b}}$ & $\nu_{\mathrm{s}}^{\mathrm{f}}$ & $\nu_{\mathrm{a}}^{\mathrm{f}}$ \\
\hline G & $3164(150)$ & $3299(123)$ & $3348(90)$ \\
G-Ne(I) & $3172(156)$ & $3301(126)$ & $3350(87)$ \\
G-Ne(II) & $3166(152)$ & $3303(134)$ & $3351(109)$ \\
G-Ne(III) & $3168(147)$ & $3302(132)$ & $3351(122)$ \\
G-Ne(IV) & $3164(152)$ & $3299(124)$ & $3348(90)$ \\
G-Ar(I) & $3172(149)$ & $3301(121)$ & $3350(81)$ \\
G-Ar(II) & $3177(124)$ & $3281(209)$ & $3344(134)$ \\
G-Ar(III) & $3169(135)$ & $3290(218)$ & $3338(139)$ \\
G-Ar(IV) & $3160(161)$ & $3299(125)$ & $3349(90)$
\end{tabular}

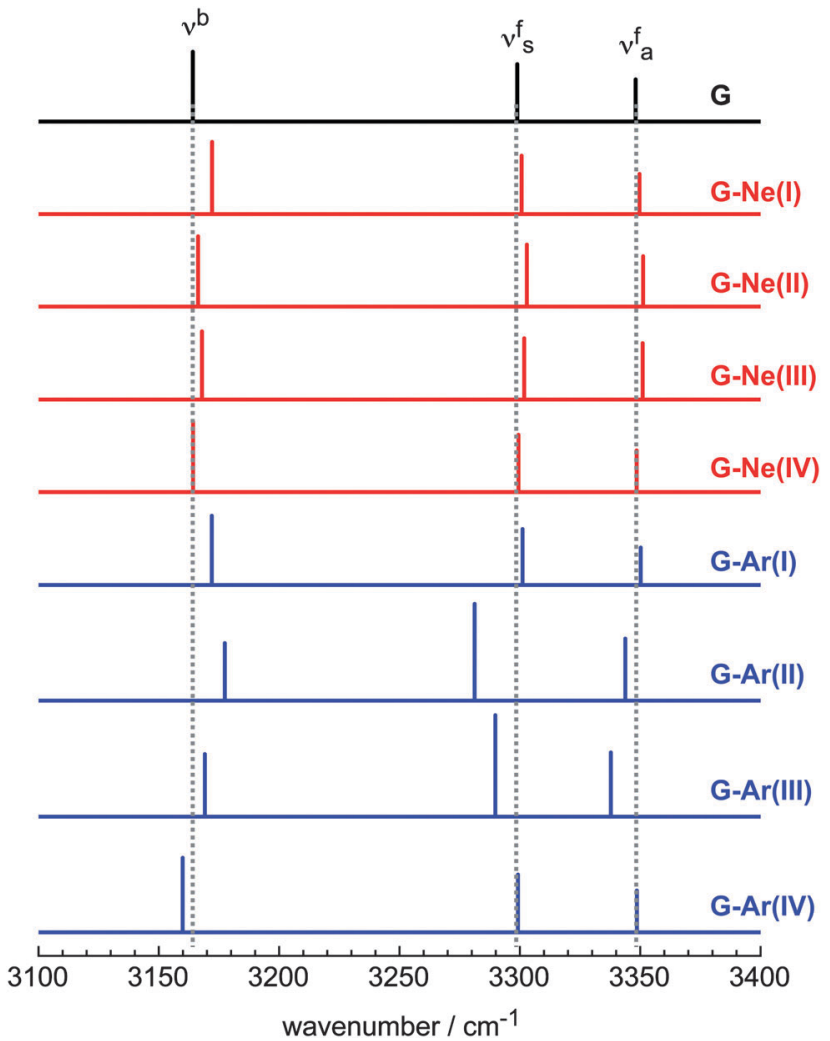

Fig. 4 Linear harmonic IR absorption spectra (scaled by 0.9586 ) of the $G$ conformer of $\mathrm{H}^{+} \mathrm{PEA}$ and various isomers of $\mathrm{G}-\mathrm{Rg}$ with $\mathrm{Rg}=\mathrm{Ar}$ and $\mathrm{Ne}$ calculated at the B3LYP-D3/aug-cc-pVTZ level.

both shorter and stronger $\mathrm{NH}^{+}-\pi$ and $\mathrm{NH}^{+}-\mathrm{Ar}$ bonds as compared to $\mathbf{G}-\mathrm{Ar}(\mathrm{I})$. However, their Ar binding energies are slightly weaker $\left(D_{0}=873\right.$ and $802 \mathrm{~cm}^{-1}$ ) due to the lack of the Ar- $\pi$ dispersion attraction. In the G-Ar(IV) isomer, Ar interacts mostly with the neutral $\pi$ electron system, and the lack of any $\mathrm{NH}^{+}-\mathrm{Ar}$ interaction leads to a quite low binding energy of $D_{0}=382 \mathrm{~cm}^{-1}$ with $R=$ $3.51 \AA$ A. These values are similar to corresponding experimental data of the neutral benzene-Ar $\operatorname{dimer}\left(R=3.58 \AA\right.$ and $D_{0}=342 \pm$ $\left.3 \mathrm{~cm}^{-1}\right) \cdot{ }^{83,84}$ Comparison of the binding energies of isomer III and IV yields the separate interaction energies of the $\mathrm{Ar}-\pi$ and $\mathrm{NH}^{+}-\mathrm{Ar}$ bonds as $\sim 400$ and $\sim 800 \mathrm{~cm}^{-1}$, respectively. Comparison of these values with the binding energy of isomer I yields a rough estimate for the steric constraint of $\sim 300 \mathrm{~cm}^{-1}$. In general, the Ar binding energies are well below the $\mathbf{G} \rightarrow \mathbf{A}$ isomerization barriers (Fig. 3), i.e. the rare gas tagging of $\mathrm{H}^{+}$PEA does not have a significant influence on the conformation of its side chain. Thus, A-Rg dimers are not considered further, because they are also not detected experimentally (Fig. 2). In general, the relative energies for the G-Ne(I-IV) isomers behave similar to those of G-Ar(I-IV), with the major difference of the much weaker bonding in the former complexes (Tables 2 and 3).

The effects of $\mathrm{Ne}$ and $\mathrm{Ar}$ complexation of $\mathbf{G}$ on the $\mathrm{N}-\mathrm{H}$ bond lengths are listed in Table 2 and the resulting linear IR absorption spectra in the $\nu_{\mathrm{NH}}$ range calculated for $\mathbf{G}-\mathrm{Rg}(\mathrm{I}-\mathrm{IV})$ are compared to that of $\mathbf{G}$ in Fig. 4 (Table 3). Due to the stronger interaction, Ar complexation exhibits larger $\nu_{\mathrm{NH}}$ shifts and is 
considered first. The $\nu_{\mathrm{NH}}$ frequencies of G-Ar(I) shift to the blue by +2 and $+8 \mathrm{~cm}^{-1}$ for $\nu_{\mathrm{s} / \mathrm{a}}^{\mathrm{f}}$ and $\nu^{\mathrm{b}}$, respectively. In contrast, for G-Ar(II/III) only $\nu^{\mathrm{b}}$ shifts to higher values (by $+13 /+5 \mathrm{~cm}^{-1}$ ), while $\nu_{\mathrm{s}}^{\mathrm{f}}$ and $\nu_{\mathrm{a}}^{\mathrm{f}}$ shift to the red by $-18 /-9$ and $-4 /-10 \mathrm{~cm}^{-1}$, respectively. This largely different behaviour can be used to distinguish between the isomers I and II/III. As expected, isomer IV exhibits only minor $\nu_{\mathrm{NH}}$ shifts $\left(<4 \mathrm{~cm}^{-1}\right)$. Due to the weaker interaction, the G-Ne(I-IV) complexes show much smaller effects. For G-Ne(I-III), all $\nu_{\mathrm{NH}}$ frequencies slightly increase upon $\mathrm{Ne}$ complexation (by 2 to $8 \mathrm{~cm}^{-1}$ ), while those of G-Ne(IV) are essentially unaffected. Therefore, the experimental $\mathrm{H}^{+}$PEA-Ne spectrum can be regarded as a close approximation to the bare $\mathrm{H}^{+}$PEA spectrum.

The three $\nu_{\mathrm{NH}}$ bands (A-C) in the IRPD spectrum of $\mathrm{H}^{+}$PEA$\mathrm{Ne}$ are observed at 3348,3299 , and $3120 \mathrm{~cm}^{-1}$ and display small incremental blue shifts of $1-3 \mathrm{~cm}^{-1}$ upon attachment of two further Ne ligands. This trend is consistent with the predictions for sequential $\mathrm{Ne}$ solvation of the three $\mathrm{NH}_{3}{ }^{+}$protons for $n=1-3$. However, the sequence of solvation in $\mathrm{H}^{+} \mathrm{PEA}-\mathrm{Ne}_{n}$ cannot be determined from the small spectral shifts and the calculations predict the same binding energy for all three binding sites to within $9 \mathrm{~cm}^{-1}$. Thus, we conclude the presence of a mixture of several isomers. The situation is different for $\mathrm{H}^{+} \mathrm{PEA}-\mathrm{Ar}_{n}$. Clearly, the $\nu_{\mathrm{a} / \mathrm{s}}^{\mathrm{f}}$ transitions (A and B) of $\mathrm{H}^{+} \mathrm{PEA}-\mathrm{Ar}$ are shifted to lower frequencies as compared to those of $\mathrm{H}^{+} \mathrm{PEA}-\mathrm{Ne}$ (by $-8 \mathrm{~cm}^{-1}$ ), and this trend is only compatible with isomers II and III. Hence, we conclude that sequential Ar solvation of the two free $\mathrm{NH}$ groups of $\mathrm{H}^{+} \mathrm{PEA}$ dominates the cluster population of $\mathrm{H}^{+} \mathrm{PEA}-\mathrm{Ar}_{n}$ with $n=1$ and 2, while clusters with an Ar binding site corresponding to isomer I appear to be significantly less abundant. The experimental preference for isomers II and III over isomer I may arise from entropic factors. Indeed, the binding free energy of isomer II calculated at room temperature is larger than that of isomer I by $365 \mathrm{~cm}^{-1}$, supporting the solvation sequence suggested for the population in the somewhat colder molecular beam.

The calculated linear IR spectra of the G-Rg dimers can be used to extrapolate from the experimental IRPD spectra of the $\mathrm{H}^{+} \mathrm{PEA}-\mathrm{Rg}_{n}$ clusters to the fundamental frequencies of bare $\mathbf{G}$. Using the IRPD spectrum of $\mathrm{H}^{+} \mathrm{PEA}-\mathrm{Ne}$ and the frequency shifts predicted for isomers I-III, we obtain experimental frequencies of the $\nu_{\mathrm{a}}^{\mathrm{f}}=3345 \pm 1$ (A), $\nu_{\mathrm{s}}^{\mathrm{f}}=3296 \pm 1$ (B), and $\nu^{\mathrm{b}}=3115 \pm$ $3 \mathrm{~cm}^{-1}$ (C) for isolated $\mathbf{G}$ (assuming the same band contour). These values deviate from those derived from the IRMPD spectrum of $\mathrm{H}^{+}$PEA by $-6,-11$, and $-28 \mathrm{~cm}^{-1}$, i.e. the IRMPD process causes a substantial blue shift in the absorption bands, which is most pronounced for the $\nu^{\mathrm{b}}$ transition (C). Such blue shifts upon IRMPD are rather uncommon. In most cases, the multiple photon absorption process causes red shifts of the order of $10-30 \mathrm{~cm}^{-1}$, respectively. ${ }^{72,73,85}$ The calculations indicate that $\mathrm{Rg}$ tagging has only a modest impact on the IR intensities. For example, the intensity changes in G-Ne(I-III) are all predicted to be below $35 \%$. Thus, the relative intensities observed in the $\mathrm{H}^{+} \mathrm{PEA}-\mathrm{Ne}$ spectrum provide reliable estimates for the relative intensities of the three $\nu_{\mathrm{NH}}$ fundamentals of $\mathbf{G}$ (to within a factor of 2), and indeed there is good correspondence between the $\mathrm{H}^{+} \mathrm{PEA}-\mathrm{Ne}$ spectrum and that calculated for G (Fig. 2). On the other hand, the relative intensity of the $\nu^{\mathrm{b}}$ transition in the IRMPD spectrum of $\mathrm{H}^{+}$PEA is largely quenched (by a factor 25), while those of $\nu_{\mathrm{a} / \mathrm{s}}^{\mathrm{f}}$ appear much less affected.

Finally, we note that the two additional peaks D and E observed in the $3150-3200 \mathrm{~cm}^{-1}$ range in all Rg-tagged spectra, which have not been identified in the IRMPD spectrum, cannot be assigned by the harmonic spectra. These peaks are attributed to overtones and/or combination bands on the basis of anharmonic calculations.

\subsection{Anharmonic calculations}

The main goals of the anharmonic calculations are (i) to investigate the effects of anharmonicity on the vibrations of the $\mathrm{NH}_{3}{ }^{+}$group with respect to both frequency and IR intensity and (ii) to suggest possible assignments for the transitions D-F in the $\mathrm{N}-\mathrm{H}$ stretch range of the IRPD spectra of $\mathrm{H}^{+} \mathrm{PEA}-\mathrm{Rg}_{n}$. To this end, anharmonic calculations are carried out as implemented in the GAUSSIAN09 package using the dispersioncorrected B3LYP-D3 functional. ${ }^{67}$ However, for computational reasons the basis set had to be reduced from aug-cc-pVTZ to cc-pVTZ. This basis set reduction is uncritical for the monomer calculations because it affects the scaled harmonic N-H stretch frequencies by only a few $\mathrm{cm}^{-1}$. Although we have calculated anharmonic spectra for both conformers of the $\mathrm{H}^{+}$PEA monomer ( $\mathbf{G}$ and $\mathbf{A}$ ) and also for the most stable G-Rg dimers, we report only the results for the $\mathbf{G}$ monomer. The results for $\mathbf{A}$ are omitted because this conformer is not observed experimentally, and the anharmonic data for the G-Rg dimers appear unreliable considering the smaller basis set and the treatment of the weak intermolecular bonds with a simple perturbation theory approach.

The previously reported IRMPD spectrum of bare $\mathrm{H}^{+}$PEA recorded in the fingerprint range $\left(650-1700 \mathrm{~cm}^{-1}\right)^{23}$ is compared in Fig. 5 to the harmonic linear IR absorption spectra of conformer $\mathbf{G}$ (unscaled and scaled) and the corresponding anharmonic IR spectrum (unscaled). Most of the transitions in this spectral range show only modest variations in frequency and relative IR intensity upon inclusion of anharmonicity, with the notable exception of the $\mathrm{NH}$ bending modes of the $\mathrm{NH}_{3}{ }^{+}$ group $\left(\beta_{\mathrm{NH}}\right)$, the aliphatic $\mathrm{CH}_{2}$ scissoring modes $\left(\beta_{\mathrm{CH}_{2}}\right)$, and the aromatic C-C stretch modes (8a, 19b) occurring in the 1400$1700 \mathrm{~cm}^{-1}$ range (Table 4 and Fig. S4 in ESI $\dagger$ ). Anharmonicity reduces the frequencies of the three $\beta_{\mathrm{NH}}$ modes $\left(45-79 \mathrm{~cm}^{-1}\right)$ more than those of the $\mathrm{C}-\mathrm{C}$ stretch and the two $\beta_{\mathrm{CH}_{2}}$ scissoring modes $\left(38-44 \mathrm{~cm}^{-1}\right)$. This changes the order of each of the transitions, which contribute to the intense experimental IRMPD bands at 1602 and $1458 \mathrm{~cm}^{-1}$. While harmonic calculations suggest that the $1602 \mathrm{~cm}^{-1}$ band is dominated by the two asymmetric $\beta_{\mathrm{NH}}$ fundamentals (93\%), the anharmonic calculations predict that the $\mathrm{C}-\mathrm{C}$ stretch $8 \mathrm{a}$ makes, via strong IR enhancement (factor 44), the predominant contribution (60\%) whereas the $\beta_{\mathrm{NH}}$ bands yield in total only $39 \%$. Similarly, the harmonic calculations predict the symmetric $\beta_{\mathrm{NH}}$ umbrella inversion as main contributor to the experimental $1458 \mathrm{~cm}^{-1}$ 

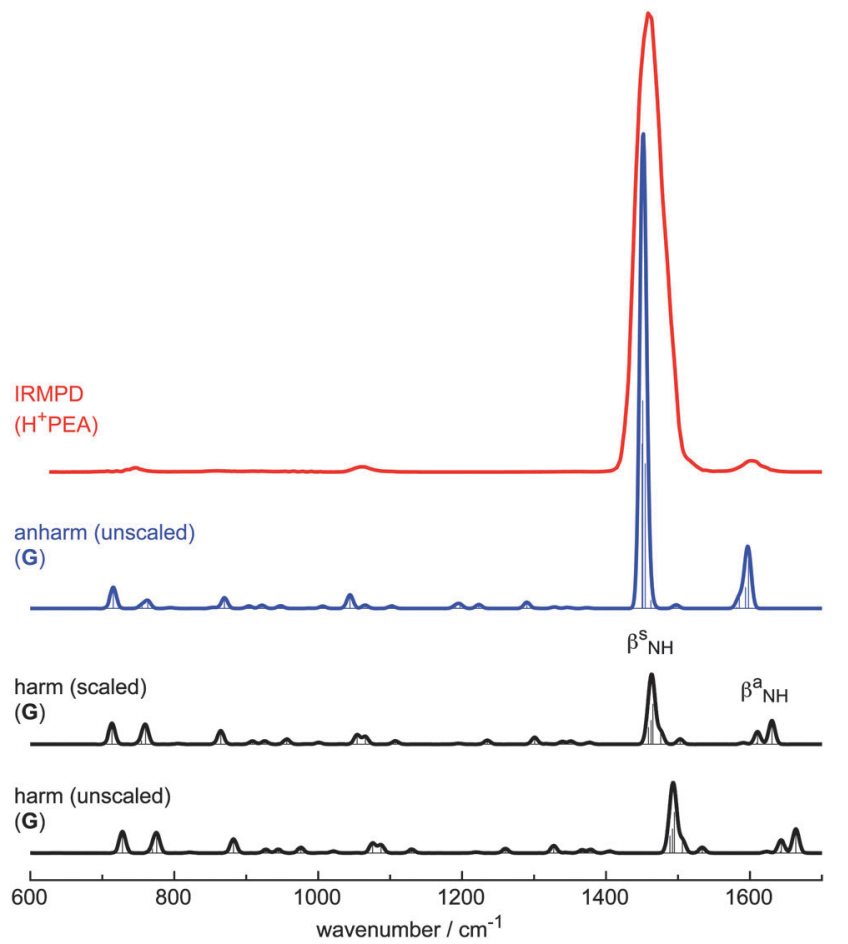

Fig. 5 IRMPD spectrum of $\mathrm{H}^{+} \mathrm{PEA}$ in the fingerprint range $\mathrm{e}^{23}$ compared to linear harmonic IR absorption spectra of the $\mathrm{G}$ conformer of $\mathrm{H}^{+} \mathrm{PEA}$ (unscaled and scaled by 0.98 ) and the corresponding anharmonic spectrum calculated at the B3LYP-D3/cc-pVTZ level. The stick spectra are convoluted by a Gaussian line profile with $10 \mathrm{~cm}^{-1}$ (FWHM). An expanded view of the theoretical spectra is offered in Fig. S3 in ESI. $\dagger$

Table 4 Harmonic and anharmonic frequencies $\left(\mathrm{cm}^{-1}\right.$, unscaled) and IR intensities $\left(\mathrm{km} \mathrm{mol}^{-1}\right)$ of selected fundamentals, overtones, and combination bands of the $\mathrm{G}$ conformer of $\mathrm{H}^{+}$PEA calculated at the B3LYP-D3/ cc-pVTZ level

\begin{tabular}{llllrr}
\hline Mode number & Modes & $\nu($ harm $)$ & $\nu($ anharm $)$ & $I($ harm $)$ & $I$ (anharm) \\
\hline 1 & $\nu_{\mathrm{NH}}\left(\nu_{\mathrm{a}}^{\mathrm{f}}\right)$ & 3497 & 3326 & 90 & 76 \\
2 & $\nu_{\mathrm{NH}}\left(\nu_{\mathrm{s}}^{\mathrm{f}}\right)$ & 3445 & 3283 & 124 & 75 \\
3 & $\nu_{\mathrm{NH}}\left(\nu^{\mathrm{b}}\right)$ & 3293 & 3061 & 167 & 124 \\
13 & $\beta_{\mathrm{NH}}^{\mathrm{a}}$ & 1664 & 1585 & 44 & 19 \\
14 & $\beta_{\mathrm{NH}}^{\mathrm{a}}$ & 1644 & 1594 & 21 & 38 \\
15 & $8 \mathrm{a}$ & 1642 & 1598 & 2 & 88 \\
16 & $8 \mathrm{~b}$ & 1623 & 1582 & 3 & 2 \\
18 & $\beta_{\mathrm{CH}}$ & 1506 & 1462 & 23 & 15 \\
19 & $\beta_{\mathrm{NH}}^{\mathrm{s}}$ & 1495 & 1450 & 74 & 303 \\
20 & $19 \mathrm{~b} / \beta_{\mathrm{NH}}^{\mathrm{s}}$ & 1492 & 1454 & 44 & 266 \\
21 & $\beta_{\mathrm{CH}}$ & 1489 & 1451 & 31 & 382 \\
54 & $\tau_{\mathrm{NH}}$ & 228 & 239 & 15 & 1 \\
57 & $\tau_{\mathrm{C}_{3} \mathrm{H}_{5}}^{\mathrm{a}}$ & 41 & 89 & 4 & 11 \\
$13+13$ & $2 \beta_{\mathrm{NH}}^{\mathrm{a}}$ & 3328 & 3157 & & 8 \\
$14+14$ & $2 \beta_{\mathrm{NH}}^{\mathrm{a}}$ & 3287 & 3184 & & 4 \\
$54+3$ & $\nu^{\mathrm{b}}+\tau_{\mathrm{NH}}$ & 3521 & 3320 & & 6 \\
$57+3$ & $\nu^{\mathrm{b}}+\tau_{\mathrm{C}_{6} \mathrm{H}_{5}}$ & 3334 & 3155 & & 19 \\
$16+13$ & $8 \mathrm{~b}+\beta_{\mathrm{NH}}^{\mathrm{a}}$ & 3287 & 3165 & & 66 \\
$15+14$ & $8 \mathrm{a}+\beta_{\mathrm{NH}}^{\mathrm{a}}$ & 3286 & 3190 & & 41 \\
& & & & &
\end{tabular}

band (43\%), while the anharmonic simulations suggest that the $\beta_{\mathrm{CH}_{2}}$ scissoring next to the aromatic ring along with the C-C stretch $19 \mathrm{~b}$ (strongly coupled to $\beta_{\mathrm{NH}}$ ) dominate the anharmonic intensities (67\%). Significantly, the sum of the absolute IR intensities of the four fundamentals near $1450 \mathrm{~cm}^{-1}$ increases from 172 to $966 \mathrm{~km} \mathrm{~mol}^{-1}$ (factor 5.6) upon inclusion of anharmonicity, which explains that this band completely dominates the convoluted theoretical anharmonic spectrum, in nearly quantitative agreement with experiment. Clearly, the harmonic linear IR absorption spectrum cannot account for the relative intensities observed in the IRMPD spectrum. Finally, we note that other factors than anharmonicity, namely those arising from nonlinearities of the IRMPD process, ${ }^{72,73}$ may provide further contributions to the deviation between the IRMPD spectrum and the simulated linear single-photon IR absorption spectrum.

The previously reported IRMPD spectrum ${ }^{23}$ of bare $\mathrm{H}^{+}$PEA and the new IRPD spectrum of $\mathrm{H}^{+} \mathrm{PEA}-\mathrm{Ne}_{2}$ recorded in the $\mathrm{N}-\mathrm{H}$ stretch range are compared in Fig. 6 to the harmonic linear IR absorption spectra of conformer $\mathbf{G}$ (unscaled and scaled) and the corresponding anharmonic IR spectrum (unscaled), with contributions of the fundamentals, first overtones, and combination bands involving two quanta (Table 4). The simulated spectra illustrate that the relative intensities of the three $\nu_{\mathrm{NH}}$ fundamentals are nearly unaffected by anharmonic effects, which is taken as strong evidence that the drastic suppression of the $\nu^{\mathrm{b}}$ band in the IRMPD spectrum of $\mathrm{H}^{+} \mathrm{PEA}$ (factor 25) as compared

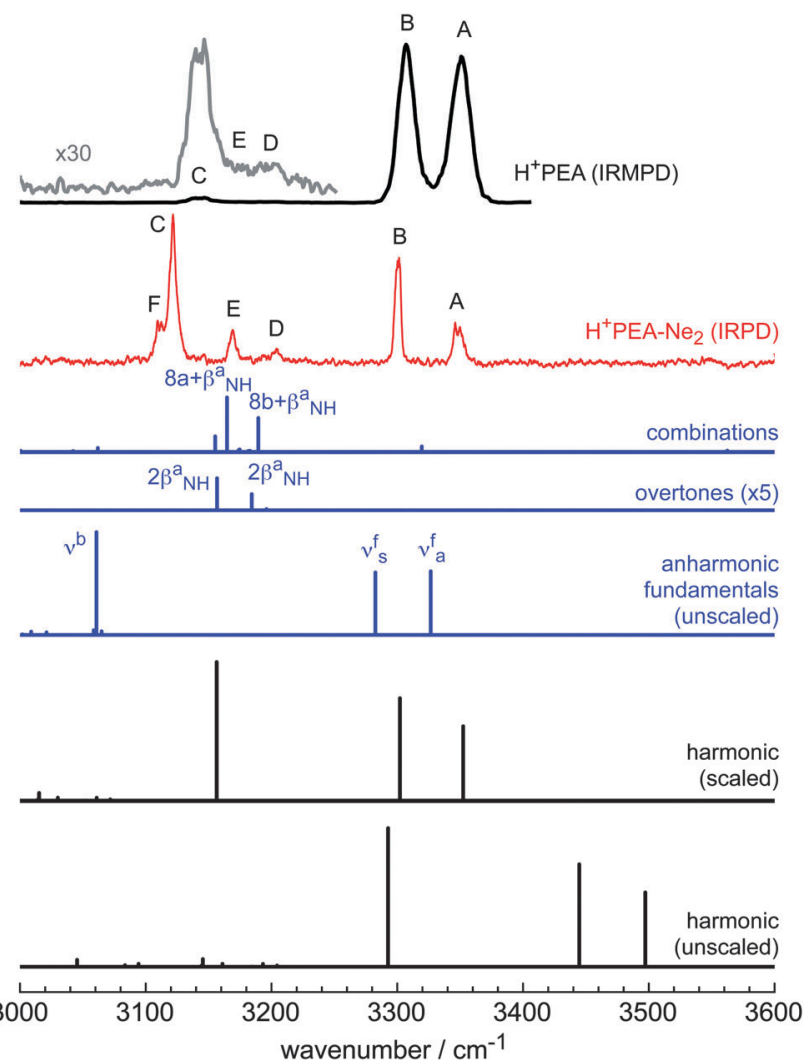

Fig. 6 IRMPD spectrum of $\mathrm{H}^{+} \mathrm{PEA} \mathrm{A}^{23}$ and IRPD spectrum of $\mathrm{H}^{+} \mathrm{PEA}-\mathrm{Ne}_{2}$ in the $\mathrm{C}-\mathrm{H} / \mathrm{N}-\mathrm{H}$ stretch range compared to linear harmonic IR absorption stick spectra of the $\mathrm{G}$ conformer of $\mathrm{H}^{+}$PEA (unscaled and scaled by 0.9586 ) and the corresponding anharmonic stick spectra calculated at the B3LYPD3/cc-pVTZ level with fundamentals, first overtones, and combination bands involving two quanta (Table 4). 
to the IRPD spectrum of $\mathrm{H}^{+} \mathrm{PEA}-\mathrm{Ne}_{2}$ is indeed a result of the multiple-photon process of IRMPD. Anharmonicity does not change much the spacing between the two free $\nu_{\mathrm{NH}}$ fundamentals. On the other hand, the bound $\mathrm{N}-\mathrm{H}$ stretch is further reduced in frequency because of its larger anharmonicity arising from the intramolecular $\mathrm{NH}^{+}-\pi$ bond. The best experimental estimate of $\nu^{\mathrm{b}}=3115 \pm 3 \mathrm{~cm}^{-1}$ derived from the $\mathrm{H}^{+} \mathrm{PEA}-\mathrm{Rg}_{n}$ spectra lies between the unscaled anharmonic and scaled harmonic values of 3061 and $3164 \mathrm{~cm}^{-1}$. Thus, also the frequency of this mode observed in the IRMPD spectrum $\left(3143 \mathrm{~cm}^{-1}\right)$ is largely affected by the multiple-photon process, with a blue shift of about $30 \mathrm{~cm}^{-1}$. The anharmonic calculations suggest two main options for the assignments of the bands D and E near 3200 and $3170 \mathrm{~cm}^{-1}$, which cannot be rationalized by fundamentals in both the harmonic and anharmonic calculations. They are also not produced by $\mathrm{Rg}$ tagging because signal in this frequency range is also observed in the IRMPD spectrum of the bare $\mathrm{H}^{+} \mathrm{PEA}$ monomer. The first option is an assignment to the first overtones of the two asymmetric $\mathrm{NH}$ bends of the $\mathrm{NH}_{3}{ }^{+}$group $\left(2 \beta_{\mathrm{NH}}^{\mathrm{a}}\right)$, with predicted anharmonic frequencies of 3184 and $3157 \mathrm{~cm}^{-1}$ and IR intensities of 4 and $8 \mathrm{~km} \mathrm{~mol}{ }^{-1}$, respectively. Concerning the calculated intensities, a more likely assignment is to the two combination bands of the aromatic $\mathrm{C}-\mathrm{C}$ stretch fundamentals with one quantum of $\mathrm{NH}$ bend, $8 \mathrm{a}+\beta_{\mathrm{NH}}^{\mathrm{a}}$ and $8 \mathrm{~b}+\beta_{\mathrm{NH}}^{\mathrm{a}}$, with similar predicted frequencies of 3190 and $3165 \mathrm{~cm}^{-1}$ but higher IR activities of 41 and $66 \mathrm{~km} \mathrm{~mol}^{-1}$, respectively. Other two-quanta combination bands in this spectral range are combinations of $\nu^{\mathrm{b}}$ with the $\mathrm{NH}_{3}{ }^{+}$torsion $\left(3155 \mathrm{~cm}^{-1}, 19 \mathrm{~km} \mathrm{~mol}^{-1}\right.$ ), which may contribute to band $\mathrm{E}$, and with the $\mathrm{C}_{6} \mathrm{H}_{5}$ torsion $\left(3320 \mathrm{~cm}^{-1}\right.$, $6 \mathrm{~km} \mathrm{~mol}^{-1}$ ), which is probably too weak to be detected (Table 4). Interestingly, combination bands involving the very intense symmetric $\mathrm{NH}$ bend $\left(\beta_{\mathrm{NH}}^{\mathrm{s}}\right)$, the $\mathrm{C}-\mathrm{C}$ stretch $19 \mathrm{~b}$, and the $\mathrm{CH}_{2}$ scissor $\left(\beta_{\mathrm{CH}_{2}}\right)$ fundamentals near $1460 \mathrm{~cm}^{-1}$, which dominate the fingerprint spectrum, do not have any significant predicted IR activity in the $\mathrm{C}-\mathrm{H}$ and $\mathrm{N}-\mathrm{H}$ stretch range, in line with the experimental observation. Moreover, no intense combination band or overtone involving two quanta is predicted close to band $\mathrm{F}$ at $\sim 3110 \mathrm{~cm}^{-1}$. Hence, at present we attribute this feature either to a sideband of band $\mathrm{C}$ arising from different $\mathrm{Ne}$ binding sites or to a higher-order combination/overtone not considered in the calculations.

Several explanations may be considered for the enormous suppression of the IR activity of the $\nu^{\mathrm{b}}$ band (band C) in the IRMPD spectrum of $\mathrm{H}^{+}$PEA (factor 25), assigned to the proton donor stretch mode of the intramolecular $\mathrm{NH}^{+}-\pi$ H-bond of $\mathbf{G}$. IRMPD relies on incoherent sequential absorption of photons resonant with a vibrational mode, with efficient intramolecular vibrational energy redistribution (IVR) between each absorption step to avoid the bottleneck arising from diagonal anharmonicity. ${ }^{72,73}$ In the $\mathrm{N}-\mathrm{H}$ stretch range, the IRMPD spectrum of $\mathrm{H}^{+}$PEA is obtained in an ion trap at room temperature, by irradiating the ions for an irradiation time up to $6 \mathrm{~s}$ with pulses from a nanosecond IR-OPO laser operating at $10 \mathrm{~Hz}$ with a relatively narrow bandwidth of $3-4 \mathrm{~cm}^{-1} \cdot{ }^{23}$ The first explanation may be large diagonal and cross anharmonicities of this vibration, which after the absorption of the first IR photon(s) shift the $\nu^{\mathrm{b}}$ transition out of resonance. In nearly all cases, anharmonicity shifts a stretch transition in sequence hot bands to lower frequencies than the fundamental, and consequently IRMPD bands are commonly shifted to the red compared to linear IR absorption spectra by up to $30 \mathrm{~cm}^{-1} \cdot{ }^{72,73}$ Our anharmonic calculations confirm that the anharmonicity of $\nu^{\mathrm{b}}$ indeed follows this expected trend (Fig. 6, Table 4). Thus, we can exclude this scenario for $\mathrm{H}^{+}$PEA here, because the IRMPD band is largely shifted to the blue. A second route of arguments utilizes the concept of IRMPD "transparency". ${ }^{8-90}$ This concept has been invoked to rationalize the low or even absent absorptions of proton donor stretch transitions of inter- and intramolecular H-bonds in IRMPD spectra, which have high IR oscillator strengths in their predicted linear IR absorption spectra. The absorption of one or more IR photons induces heating of the (cluster) ions, which reduces the strength of the $\mathrm{H}$-bond or even leads to its rupture. As a result, the vibrational frequency of the proton donor stretch mode of the internally excited ion shifts largely to the blue compared to the fundamental value and quickly runs out of resonance with the exciting photon frequency as the internal energy rises. Therefore, the ion can absorb only a limited number of IR photons, which may often be insufficient for reaching the lowest dissociation limit to generate the IRMPD signal. In the present case of the $\mathbf{G}$ conformer of $\mathrm{H}^{+} \mathrm{PEA}$, the $\nu^{\mathrm{b}}$ frequency of cold ions is estimated as $\nu^{\mathrm{b}}=3115 \pm 3 \mathrm{~cm}^{-1}$ from the IRPD spectra of cold $\mathrm{H}^{+} \mathrm{PEA}-\mathrm{Ne}_{n}$ clusters. The IRMPD spectrum of $\mathrm{H}^{+} \mathrm{PEA}$ does actually not show any signal at all at this frequency (Fig. 2), indicating that the IRMPD band $\mathrm{C}$ arises barely from the hot ion population in the room-temperature trap. Apparently, the population of such hot ions is relatively low giving rise to the low IRMPD yield for band C. In addition, the potential energy surface in Fig. 3 suggests that the barriers for conformational reorganization of the side chain in $\mathrm{H}^{+} \mathrm{PEA}$ are all below $3000 \mathrm{~cm}^{-1}$. Thus, the excitation of a single $\nu^{\mathrm{b}}$ quantum of the cold $\mathbf{G}$ conformer $\left(3115 \mathrm{~cm}^{-1}\right)$ can in principle lead to the rupture of the intermolecular $\mathrm{H}$-bond and even induce isomerization to the A conformer. Although, when considering the density of states of the $\mathbf{G}$ and $\mathbf{A}$ conformers, this process is unlikely to occur for low internal energies, excitation of $\mathbf{G}$ by one or a few IR photons will, after IVR into the flexible conformational coordinates, trigger a large amplitude motion along the $\mathbf{G} \leftrightarrow \mathbf{A}$ transformation coordinate. This process will weaken or even break the H-bond, leading to a substantial increase in the proton donor stretch frequency via significant cross anharmonicities of $\nu^{\mathrm{b}}$ with low-frequency modes. As an example, the strong couplings between the high-frequency $\mathrm{N}-\mathrm{H}$ stretch coordinates and the low-frequency $\mathbf{G} \leftrightarrow \mathbf{A}$ isomerization coordinate $\theta_{\mathrm{C} 1 \mathrm{C} 7 \mathrm{C} 8 \mathrm{~N}}$ are visualized in Fig. S3 in ESI, $\dagger$ where the $\mathrm{N}-\mathrm{H}$ bond lengths and stretch frequencies are plotted as a function of $\theta_{\mathrm{C} 1 \mathrm{C} 7 \mathrm{C} 8 \mathrm{~N}}$ for geometries along the path shown in Fig. 3. The resulting linear IR absorption spectra are also shown for selected $\theta_{\mathrm{C} 1 \mathrm{C} 7 \mathrm{C} 8 \mathrm{~N}}$ values in Fig. S3 in ESI. $\dagger$ These spectra illustrate in a quantitative fashion that already modest excitation of the isomerization mode (with amplitudes of less than $10^{\circ}$ 
away from the global minimum $\mathbf{G}$ at $\Delta \theta= \pm 54^{\circ}$ ) will already induce a substantial blue shift in the $\nu^{\mathrm{b}}$ transition (the zeropoint excursion is estimated as $\Delta \theta= \pm 4^{\circ}$ from the harmonic frequency of the corresponding normal mode of $44 \mathrm{~cm}^{-1}$ ). Thus, the substantial blue shift of $\nu^{\mathrm{b}}$ in the IRMPD spectrum is based on cross anharmonicities rather than on diagonal terms (diagonal anharmonicity reduces the frequency of the $n=0-1$ fundamental of $\nu^{\mathrm{b}}$ at $3061 \mathrm{~cm}^{-1}$ to $2881 \mathrm{~cm}^{-1}$ for the $n=1-2$ transition). In contrast to the broad-band IR-FELs (15-30 $\mathrm{cm}^{-1}$ bandwidth at $3000 \mathrm{~cm}^{-1}$ ), this effect is particularly crucial for the relatively narrow bandwidth of the IR-OPO laser employed for the IRMPD spectrum of $\mathrm{H}^{+}$PEA in the $\mathrm{N}-\mathrm{H}$ stretch range (3-4 $\left.\mathrm{cm}^{-1}\right)$. In summary, it is thought that band $\mathrm{C}$ does not arise from vibrationally cold ions but from IRMPD of initially thermally preexcited ions, whose population is small, giving rise to the small signal. In contrast to $\nu^{\mathrm{b}}$, the free $\nu_{\mathrm{a} / \mathrm{s}}^{\mathrm{f}}$ transitions do not suffer from such large frequency shifts upon internal heating and thus exhibit IRMPD intensities which are roughly proportional to their linear IR absorption cross sections. Nonetheless, also these free $\nu_{\mathrm{NH}}$ bands exhibit small but noticeable blue shifts in the IRMPD spectrum due to anharmonic couplings with other modes.

\subsection{Comparison to neutral PEA}

It is illustrative to compare the structural and electronic properties of the $\mathbf{G}$ conformer of $\mathrm{H}^{+}$PEA with those of the most stable neutral PEA isomer to evaluate the effects of protonation on the charge distribution, geometry, and vibrational properties. The two most stable PEA isomers, denoted conformer $\mathbf{C}$ and $\mathbf{B},{ }^{3,4,7,10,26,34}$ are essentially isoenergetic and have both a gauche conformation with an intramolecular $\mathrm{NH}-\pi \mathrm{H}$-bond. While most previous calculations predict the $\mathbf{C}$ isomer to be slightly more stable than $\mathbf{B},{ }^{4,7,10,26,34}$ the B3LYP-D3/aug-cc-pVTZ level slightly favours B over C by $\Delta E_{0}=27 \mathrm{~cm}^{-1}$. Detailed structural parameters for these molecules are given in Fig. S1 in ESI, $\dagger$ while the charge distributions are compared in Fig. S2 in ESI. $\dagger$ The proton affinity, evaluated as the difference in the energies between $\mathbf{G}$ and $\mathbf{B}$, is obtained as $932.6 \mathrm{~kJ} \mathrm{~mol}^{-1}$ and compares favourably with a recent value determined by mass spectrometry, $925 \pm 5 \mathrm{~kJ} \mathrm{~mol}^{-1}, 91$ which is slightly larger than earlier values $\left(\sim 915 \mathrm{~kJ} \mathrm{~mol}^{-1}\right) \cdot{ }^{92,93}$ Although one has to bear in mind that these mass spectrometric experiments are not isomer-selective, the agreement is reasonable and confirms that the chosen theoretical level describes the energetic effects of protonation to satisfactory accuracy. As discussed above, the NBO analysis shows that the positive charge in $\mathbf{G}$ is mainly localized on the side chain $(q=967 \mathrm{me})$, while that of neutral PEA is essentially neutral ( $q=31$ me for $\mathbf{C}$ ), indicating that the positive charge of the excess proton largely remains on the $-\mathrm{CH}_{2}-\mathrm{NH}_{3}{ }^{+}$moiety. As expected, protonation drastically strengthens the intramolecular $\mathrm{NH}^{(+)}-\pi$ interaction leading to substantially shorter contacts between the NH proton and the aromatic ring (2.93 $\AA$ versus $3.35 \AA$ ). At the same time, the energetic difference between the most stable gauche and least stable anti isomer increases from 1.9 to $18.7 \mathrm{~kJ} \mathrm{~mol}^{-1}$.

Protonation at the $\mathrm{N}$-terminus also leads to a small average elongation of the $\mathrm{N}-\mathrm{H}$ bonds (by $11 \mathrm{m \AA}$ ) and simultaneously to
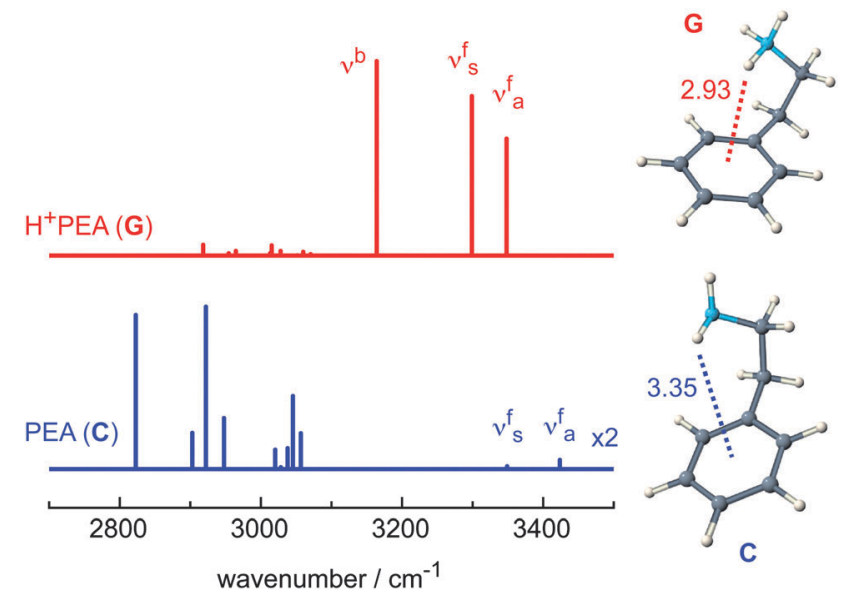

Fig. 7 Comparison of the linear harmonic IR absorption stick spectra (scaled by 0.9586 ) of the $\mathbf{G}$ conformer of $\mathrm{H}^{+} \mathrm{PEA}$ and the $\mathbf{C}$ conformer of neutral $P E A$ in the $\mathrm{C}-\mathrm{H} / \mathrm{N}-\mathrm{H}$ stretch range calculated at the B3LYP-D3/ aug-cc-pVTZ level.

an elongation of the neighbouring $\mathrm{N}-\mathrm{C}$ bond (by $58 \mathrm{m \AA}$ ). All other bond length changes are less significant. These structural changes induced by protonation translate directly into the vibrational properties and the corresponding IR spectra, which are compared in Fig. 7 in the $\mathrm{C}-\mathrm{H} / \mathrm{N}-\mathrm{H}$ stretch range for the $\mathbf{G}$ and $\mathbf{C}$ conformers. Clearly, protonation has a profound effect on both the frequencies and IR intensities of the $\nu_{\mathrm{NH}}$ and $\nu_{\mathrm{CH}}$ fundamentals. Protonation induces large red shifts in the (averaged) $\nu_{\mathrm{NH}}$ frequencies (by $-117 \mathrm{~cm}^{-1}$ ) and a strong enhancement in their IR intensity ( $\sim$ factor 40 ), so that the $\nu_{\mathrm{NH}}$ bands are readily observed in the IR(M)PD spectra of $\mathrm{H}^{+} \mathrm{PEA}\left(-\mathrm{Rg}_{n}\right)$. In contrast, the IR activities of the $\nu_{\mathrm{CH}}$ fundamentals drastically drop upon protonation to intensities below $10 \mathrm{~km} \mathrm{~mol}{ }^{-1}$, which is below the current detection limit. Interestingly, the isomer-selective IR spectra of the various PEA conformers have not been reported yet. To this end, we have recorded them recently (see Fig. S5 in ESI $\dagger$ for the C isomer) and will discuss them elsewhere. Nonetheless, the isomer-selective Raman spectra of four PEA isomers are available $^{10}$ and the observed frequencies show good agreement with those calculated here.

\section{Concluding remarks}

The importance of dispersion and anharmonicity of the ammonium group on the cation- $\pi$ interaction in the prototypical protonated phenylethylamino neurotransmitter $\mathrm{H}^{+}$PEA are revealed by anharmonic vibrational calculations at the dispersion-corrected B3LYP-D3/(aug-)cc-pVTZ level and linear IRPD spectra of cold $\mathrm{H}^{+} \mathrm{PEA}$ ions in the $\mathrm{N}-\mathrm{H}$ stretch range using rare gas tagging with $\mathrm{Ne}$ and Ar ligands. Because of the weak interaction, the singlephoton IRPD spectra of $\mathrm{H}^{+} \mathrm{PEA}-\mathrm{Ne}_{n}$ provide a very close approximation to the linear IR absorption spectrum of bare $\mathrm{H}^{+} \mathrm{PEA}$ with respect to both frequencies and IR intensities. In agreement with previous IRMPD spectra of $\mathrm{H}^{+}$PEA ions recorded in 
room temperature traps ${ }^{23}$ the analysis of the IRPD spectra of $\mathrm{H}^{+} \mathrm{PEA}-\mathrm{Rg}_{n}$ clusters in the cold molecular beam indicates the presence of a single gauche conformer $\mathbf{G}$, which is predicted as most stable isomer on the $\mathrm{H}^{+}$PEA potential energy surface. The barriers for isomerization toward the less stable anti isomer $\mathbf{A}$ are significantly larger than the binding energy of the Rg atoms so that tagging has essentially no effect on the $\mathrm{H}^{+} \mathrm{PEA}$ conformation. Isomer $\mathbf{G}$ is stabilized by an intramolecular cation $-\pi$ interaction, and the resulting $\mathrm{NH}^{+}-\pi$ bond experiences an additional stabilization of 4-5 $\mathrm{kJ} \mathrm{mol}^{-1}$ upon inclusion of dispersion interactions. Comparison with neutral PEA reveals that protonation induces a conformational locking (similar to hydration of neutral PEA). While for PEA all four close-lying low-energy isomers with an energy spread of less than $2 \mathrm{~kJ} \mathrm{~mol}^{-1}$ are observed in molecular beam experiments, for $\mathrm{H}^{+}$PEA the energy spread between the two predicted isomers is rather large $\left(18.7 \mathrm{~kJ} \mathrm{~mol}^{-1}\right)$ and only one isomer is detected both in molecular beams and in room temperature traps. Protonation of the amino group weakens the $\mathrm{N}-\mathrm{H}$ bonds, and the resulting enhanced acidity - along with the large excess positive charge, which is mostly localized on the terminal $\mathrm{NH}_{3}{ }^{+}$group - strengthens its $\mathrm{H}$-bonds involved in both intra- and intermolecular solvation. The previously reported room-temperature IRMPD spectrum of $\mathrm{H}^{+} \mathrm{PEA}$ shows significant deviations from the linear IRPD spectra of the cold $\mathrm{H}^{+} \mathrm{PEA}-\mathrm{Rg}_{n}$ clusters. The anharmonic calculations suggest that cross anharmonicities in connection with (initial) internal energy are important factors, which determine the different appearance of the IRMPD spectrum. They explain the substantial blue shift of the proton donor $\mathrm{N}-\mathrm{H}$ stretch band involved in the intramolecular cation- $\pi \mathrm{H}$-bond and its large intensity suppression in the IRMPD spectrum of $\mathrm{H}^{+}$PEA, an observation previously made in IRMPD spectra of related protonated phenylalkylamines ${ }^{23}$ and phosphopeptide ions,${ }^{87}$ as well as in our unpublished IRMPD spectra of protonated histidine, dopamine, and serotonin. The analysis of the couplings between the high-frequency $\mathrm{N}-\mathrm{H}$ stretch and the low-frequency $\mathbf{G} \leftrightarrow \mathbf{A}$ isomerization coordinates provides an explanation for the unusual and substantial blue shift of the proton donor $\mathrm{N}-\mathrm{H}$ stretch band (of $\sim 30 \mathrm{~cm}^{-1}$ ) observed in the IRMPD spectrum of $\mathbf{G}$, indicating that the isomerization coordinate is largely involved in thermal heating of $\mathbf{G}$ during the IRMPD process. In the fingerprint range, the anharmonic calculations reveal rather large effects on the predicted IR intensities and frequencies, in particular for the $\mathrm{NH}_{3}{ }^{+}$bending modes $\left(\beta_{\mathrm{NH}}\right)$ but also for the nearby aromatic C-C stretch $(8 \mathrm{a}, 8 \mathrm{~b}, 19)$ and aliphatic $\beta_{\mathrm{CH}_{2}}$ modes. Apparently, an anharmonic vibrational analysis is required for a correct assignment of the spectrum observed in the fingerprint range for such systems bearing an intramolecular $\mathrm{NH}^{+}-\pi \mathrm{H}$-bond.

This work on the $\mathrm{H}^{+} \mathrm{PEA}-\mathrm{Rg}_{n}$ clusters constitutes the first step in mimicking natural conditions of this biologically relevant molecular ion. After the thorough spectroscopic description of the $\mathrm{H}^{+} \mathrm{PEA}$ monomer, further efforts include the application of the same experimental and theoretical techniques to $\mathrm{H}^{+} \mathrm{PEA}-$ $\left(\mathrm{H}_{2} \mathrm{O}\right)_{n}$ clusters to follow the evolution of microhydration toward the bulk limit relevant for neurotransmission phenomena under physiological conditions.

\section{Acknowledgements}

This work was supported by TU Berlin, the Deutsche Forschungsgemeinschaft (DO 729/3), and the German-Israeli Foundation (G.I.F. 1164-158.5/2011). We thank Ilana Bar (Ben-Gurion University of the Negev) for fruitful discussions. A.B. acknowledges support from an IPODI fellowship. The research leading to these results also has received funding from the People Programme (Marie Curie Actions) of the European Union's Seventh Framework Programme (FP7/2007-2013) under REA grant agreement no. 600209 (TU Berlin/IPODI). Financial support by the Università di Roma La Sapienza is also gratefully acknowledged.

\section{References}

1 R. A. Webster, Neurotransmitters, Drugs and Brain Function, John Wiley \& Sons, New York, 2002.

2 M. Eichelbaum, B. Testa and A. Somogyi, Stereochemical Aspects of Drug Action and Disposition, Springer, Heidelberg, 2003.

3 S. J. Martinez, J. C. Alfano and D. H. Levy, J. Mol. Spectrosc., 1993, 158, 82-92.

4 P. D. Godfrey, L. D. Hatherley and R. D. Brown, J. Am. Chem. Soc., 1995, 117, 8204-8210.

5 L. C. Snoek, T. Van Mourik and J. P. Simons, Mol. Phys., 2003, 101, 1239-1248.

6 P. Carcabal, L. C. Snoek and T. Van Mourik, Mol. Phys, 2005, 103, 1633-1639.

7 J. C. Lopez, V. Cortijo, S. Blanco and J. L. Alonso, Phys. Chem. Chem. Phys., 2007, 9, 4521-4527.

8 T. A. LeGreve, E. E. Baquero and T. S. Zwier, J. Am. Chem. Soc., 2007, 129, 4028-4038.

9 J. L. Alonso, M. E. Sanz, J. C. Lopez and V. Cortijo, J. Am. Chem. Soc., 2009, 131, 4320-4326.

10 A. Golan, N. Mayorkas, S. Rosenwaks and I. Bar, J. Chem. Phys., 2009, 131, 024305.

11 C. Cabezas, M. Varela, W. Caminati, S. Mata, J. C. Lopez and J. L. Alonso, J. Mol. Spectrosc., 2011, 268, 42-46.

12 H. Mitsuda, M. Miyazaki, I. B. Nielsen, P. Carcabal, C. Dedonder, C. Jouvet, S. Ishiuchi and M. Fujii, J. Phys. Chem. Lett., 2010, 1, 1130-1133.

13 S. Ishiuchi, H. Mitsuda, T. Asakawa, M. Miyazaki and M. Fujii, Phys. Chem. Chem. Phys., 2011, 13, 7812-7820.

14 S. Melandri, A. Merloni and A. Maris, ChemPhysChem, 2012, 13, 3504-3509.

15 N. Mayorkas, S. Izbitski, A. Bernat and I. Bar, J. Phys. Chem. Lett., 2012, 3, 603-607.

16 N. A. Macleod and J. P. Simons, Phys. Chem. Chem. Phys., 2003, 5, 1123-1129.

17 N. A. Macleod and J. P. Simons, Mol. Phys., 2006, 104, 3317-3328.

18 T. D. Vaden, T. de Boer, N. A. MacLeod, E. M. Marzluff, J. P. Simons and L. C. Snoek, Phys. Chem. Chem. Phys., 2007, 9, 2549-2555. 
19 G. Gregoire, C. Jouvet, C. Dedonder and A. L. Sobolewski, Chem. Phys., 2006, 324, 398-404.

20 A. Lagutschenkov, J. Langer, G. Berden, J. Oomens and O. Dopfer, Phys. Chem. Chem. Phys., 2011, 13, 15644-15656.

21 A. Lagutschenkov, J. Langer, G. Berden, J. Oomens and O. Dopfer, Phys. Chem. Chem. Phys., 2011, 13, 2815-2823.

22 A. Lagutschenkov, J. Langer, G. Berden, J. Oomens and O. Dopfer, J. Phys. Chem. A, 2010, 114, 13268-13276.

23 B. Chiavarino, M. E. Crestoni, M. Schütz, A. Bouchet, S. Piccirillo, V. Steinmetz, O. Dopfer and S. Fornarini, J. Phys. Chem. A, 2014, 118, 7130-7138.

24 L. C. Snoek, T. van Mourik, P. Carcabal and J. P. Simons, Phys. Chem. Chem. Phys., 2003, 5, 4519-4526.

25 N. A. Macleod and J. P. Simons, Phys. Chem. Chem. Phys., 2004, 6, 2821-2826.

26 J. Yao, H. S. Im, M. Foltin and E. R. Bernstein, J. Phys. Chem. A, 2000, 104, 6197-6211.

27 R. Brause, H. Fricke, M. Gerhards, R. Weinkauf and K. Kleinermanns, Chem. Phys., 2006, 327, 43-53.

28 T. S. Zwier, J. Phys. Chem. A, 2001, 105, 8827-8839.

29 E. G. Robertson and J. P. Simons, Phys. Chem. Chem. Phys., 2001, 3, 1-18.

30 T. A. LeGreve, W. H. James and T. S. Zwier, J. Phys. Chem. A, 2009, 113, 399-410.

31 S. Melandri, A. Maris, B. M. Giuliano, L. B. Favero and W. Caminati, Phys. Chem. Chem. Phys., 2010, 12, 10210-10214.

32 N. Mayorkas, S. Cohen, H. Sachs and I. Bar, RSC Adv., 2014, 4, 58752-58757.

33 M. Xie, J. Qi and J. Hu, J. Phys. Chem. A, 2011, 115, 3060-3067.

34 J. A. Dickinson, M. R. Hockridge, R. T. Kroemer, E. G. Robertson, J. P. Simons, J. McCombie and M. Walker, J. Am. Chem. Soc., 1998, 120, 2622-2632.

35 M. R. Hockridge and E. G. Robertson, J. Phys. Chem. A, 1999, 103, 3618-3628.

36 M. Schmitt, M. Bohm, C. Ratzer, C. Vu, L. Kalkman and W. L. Meerts, J. Am. Chem. Soc., 2005, 127, 10356-10364.

37 R. Weinkauf, F. Lehrer, E. W. Schlag and A. Metsala, Faraday Discuss., 2000, 115, 363-381.

38 G. Feraud, M. Broquier, C. Dedonder-Lardeux, G. Gregoire, S. Soorkia and C. Jouvet, Phys. Chem. Chem. Phys., 2014, 16, 5250-5259.

39 E. J. Bieske and O. Dopfer, Chem. Rev., 2000, 100, 3963-3998.

40 R. V. Olkhov and O. Dopfer, Chem. Phys. Lett., 1999, 314, 215-222.

41 N. Solcà and O. Dopfer, J. Phys. Chem. A, 2001, 105, 5637-5645.

42 N. Solcà and O. Dopfer, J. Chem. Phys., 2004, 120, 10470.

43 M. P. Gaigeot, Phys. Chem. Chem. Phys., 2010, 12, 3336-3359.

44 A. Sediki, L. C. Snoek and M. P. Gaigeot, Int. J. Mass Spectrom., 2011, 308, 281-288.

45 T. Fornaro, M. Biczysko, S. Monti and V. Barone, Phys. Chem. Chem. Phys., 2014, 16, 10112-10128.

46 O. Dopfer, Int. Rev. Phys. Chem., 2003, 22, 437-495.
47 O. Dopfer, Z. Phys. Chem., 2005, 219, 125-168.

48 N. Solcà and O. Dopfer, Angew. Chem., Int. Ed., 2002, 41, 3628.

49 N. Solcà and O. Dopfer, Angew. Chem., Int. Ed., 2003, 42, 1537.

50 N. Solcà and O. Dopfer, Chem. - Eur. J., 2003, 9, 3154.

51 N. Solcà and O. Dopfer, J. Phys. Chem. A, 2005, 109, 6174-6186.

52 H. S. Andrei, S. A. Nizkorodov and O. Dopfer, Angew. Chem., 2007, 119, 4838-4840.

53 H. S. Andrei, N. Solca and O. Dopfer, Angew. Chem., Int. Ed., 2008, 47, 395.

54 A. Patzer, S. Chakraborty, N. Solca and O. Dopfer, Angew. Chem., Int. Ed., 2010, 49, 10145-10148.

55 A. Patzer, M. Zimmermann, I. Alata, C. Jouvet and O. Dopfer, J. Phys. Chem. A, 2010, 114, 12600-12604.

56 A. Patzer, M. Schütz, T. Möller and O. Dopfer, Angew. Chem., Int. Ed., 2012, 51, 4925-4929.

57 A. Patzer, M. Schütz, C. Jouvet and O. Dopfer, J. Phys. Chem. A, 2013, 117, 9785-9793.

58 M. Savoca, J. Langer and O. Dopfer, Angew. Chem., Int. Ed., 2013, 52, 1568-1571.

59 M. Savoca, M. A. R. George, J. Langer and O. Dopfer, Phys. Chem. Chem. Phys., 2013, 15, 2774-2781.

60 M. A. R. George, M. Savoca and O. Dopfer, Chem. - Eur. J., 2013, 19, 15315-15328.

61 J. Klyne, M. Schmies, M. Fujii and O. Dopfer, J. Phys. Chem. B, 2015, 119, 1388-1406.

62 M. Schmies, A. Patzer, M. Schütz, M. Miyazaki, M. Fujii and O. Dopfer, Phys. Chem. Chem. Phys., 2014, 16, 7980-7995.

63 J. Klyne, M. Schmies and O. Dopfer, J. Phys. Chem. B, 2014, 118, 3005-3017.

64 M. Schmies, M. Miyazaki, M. Fujii and O. Dopfer, J. Chem. Phys., 2014, 141, 214301.

65 K. Sakota, M. Schütz, M. Schmies, R. Moritz, A. Bouchet, T. Ikeda, Y. Kuono, H. Sekiya and O. Dopfer, Phys. Chem. Chem. Phys., 2014, 16, 3798-3806.

66 K. Tanabe, M. Miyazaki, M. Schmies, A. Patzer, M. Schütz, H. Sekiya, M. Sakai, O. Dopfer and M. Fujii, Angew. Chem., Int. Ed., 2012, 51, 6604-6607.

67 M. J. Frisch, G. W. Trucks, H. B. Schlegel, G. E. Scuseria, M. A. Robb, J. R. Cheeseman, G. Scalmani, V. Barone, B. Mennucci, G. A. Petersson, H. Nakatsuji, M. Caricato, X. Li, H. P. Hratchian, A. F. Izmaylov, J. Bloino, G. Zheng, J. L. Sonnenberg, M. Hada, M. Ehara, K. Toyota, R. Fukuda, J. Hasegawa, M. Ishida, T. Nakajima, Y. Honda, O. Kitao, H. Nakai, T. Vreven, J. A. Montgomery Jr., J. E. Peralta, F. Ogliaro, M. Bearpark, J. J. Heyd, E. Brothers, K. N. Kudin, V. N. Staroverov, R. Kobayashi, J. Normand, K. Raghavachari, A. Rendell, J. C. Burant, S. S. Iyengar, J. Tomasi, M. Cossi, N. Rega, N. J. Millam, M. Klene, J. E. Knox, J. B. Cross, V. Bakken, C. Adamo, J. Jaramillo, R. Gomperts, R. E. Stratmann, O. Yazyev, A. J. Austin, R. Cammi, C. Pomelli, J. W. Ochterski, R. L. Martin, K. Morokuma, V. G. Zakrzewski, G. A. Voth, P. Salvador, J. J. Dannenberg, S. Dapprich, A. D. Daniels, Ö. Farkas, J. B. Foresman, J. V. Ortiz, J. Cioslowski and D. J. Fox, GAUSSIAN09, D.01, Gaussian, Inc., Wallingford CT, 2009. 
68 S. Grimme, J. Antony, S. Ehrlich and H. Krieg, J. Chem. Phys., 2010, 132, 154104.

69 V. Barone, J. Chem. Phys., 2005, 122, 014108.

70 J. Bloino and V. Barone, J. Chem. Phys., 2012, 136, 124108.

71 V. Barone, M. Biczysko and J. Bloino, Phys. Chem. Chem. Phys., 2014, 16, 1759-1787.

72 J. Oomens, B. G. Sartakov, G. Meijer and G. von Helden, Int. J. Mass Spectrom., 2006, 254, 1-19.

73 P. Parneix, M. Basire and F. Calvo, J. Phys. Chem. A, 2013, 117, 3954-3959.

74 E. J. Bieske, S. A. Nizkorodov, O. Dopfer, J. P. Maier, R. J. Stickland, B. J. Cotterell and B. J. Howard, Chem. Phys. Lett., 1996, 250, 266-272.

75 O. Dopfer, S. A. Nizkorodov, M. Meuwly, E. J. Bieske and J. P. Maier, Int. J. Mass Spectrom. Ion Processes, 1997, 167-168, 637.

76 N. M. Lakin, O. Dopfer, M. Meuwly, B. J. Howard and J. P. Maier, Mol. Phys., 2000, 98, 63.

77 N. M. Lakin, O. Dopfer, B. J. Howard and J. P. Maier, Mol. Phys., 2000, 98, 81.

78 N. M. Lakin, R. V. Olkhov and O. Dopfer, Faraday Discuss., 2001, 118, 455.

79 F. M. Pasker, N. Solcà and O. Dopfer, J. Phys. Chem. A, 2006, 110, 12793-12804.

80 N. Solcà and O. Dopfer, Chem. Phys. Lett., 2000, 325, 354-359.

81 N. Solcà and O. Dopfer, J. Mol. Struct., 2001, 563-564, 241-244.
82 J. O. Hirschfelder, C. F. Curtis and R. B. Bird, Molecular Theory of Gases and Liquids, Wiley, New York, 1954.

83 H. J. Neusser and H. Krause, Chem. Rev., 1994, 94, 1829.

84 J. R. Gascooke and W. D. Lawrance, J. Phys. Chem. A, 2000, 104, 10328.

85 D. Zhao, J. Langer, J. Oomens and O. Dopfer, J. Chem. Phys., 2009, 131, 184307.

86 T. I. Yacovitch, N. Heine, C. Brieger, T. Wende, C. Hock, D. M. Neumark and K. R. Asmis, J. Phys. Chem. A, 2013, 117, 7081-7090.

87 F. Turecek, C. L. Moss, I. Pikalov, R. Pepin, K. Gulyuz, N. C. Polfer, M. F. Bush, J. Brown, J. Williams and K. Richardson, Int. J. Mass Spectrom., 2013, 354, 249-256.

88 D. Wang, K. Gulyuz, C. N. Stedwell, L. Yu and N. C. Polfer, Int. J. Mass Spectrom., 2012, 330, 144-151.

89 N. Heine, T. I. Yacovitch, F. Schubert, C. Brieger, D. M. Neumark and K. R. Asmis, J. Phys. Chem. A, 2014, 118, 7613-7622.

90 L. Jiang, S. T. Sun, N. Heine, J. W. Liu, T. I. Yacovitch, T. Wende, Z. F. Liu, D. M. Neumark and K. R. Asmis, Phys. Chem. Chem. Phys., 2014, 16, 1314-1318.

91 A. M. Cardoso, S. l. M. G. Alexandre, C. M. F. Barros, A. J. Ferrer-Correia and N. M. M. Nibbering, Int. J. Mass Spectrom. Ion Processes, 1998, 172, 123-127.

92 S. A. McLuckey, D. Cameron and R. G. Cooks, J. Am. Chem. Soc., 1981, 103, 1313-1317.

93 J. Cao and J. L. Holmes, Int. J. Mass Spectrom., 2000, 195-196, 525-532. 